\title{
Ischemia/Reperfusion Induces Interferon-Stimulated Gene Expression in Microglia
}

\author{
๑Dshley McDonough, ${ }^{1 \star}$ ๑Richard V. Lee, ${ }^{1 \star}$ Shahani Noor, ${ }^{1}$ @Chungeun Lee, ${ }^{1}$ Thu Le, ${ }^{1}$ @Michael Iorga, ${ }^{1}$ \\ Jessica L.H. Phillips, ${ }^{1}$ Sean Murphy, ${ }^{2}$ TThomas Möller, ${ }^{1}$ and ${ }^{-J o n a t h a n ~ R . ~ W e i n s t e i n ~}{ }^{1,2}$ \\ ${ }^{1}$ Department of Neurology and ${ }^{2}$ Department of Neurological Surgery, School of Medicine, University of Washington, Seattle, Washington 98195
}

Innate immune signaling is important in the pathophysiology of ischemia/reperfusion (stroke)-induced injury and recovery. Several lines of evidence support a central role for microglia in these processes. Recent work has identified Toll-like receptors (TLRs) and type I interferon (IFN) signaling in both ischemia/reperfusion-induced brain injury and ischemic preconditioning-mediated neuroprotection. To determine the effects of "ischemia/reperfusion-like" conditions on microglia, we performed genomic analyses on wild-type (WT) and $T L R 4^{-1-}$ cultured microglia after sequential exposure to hypoxia/hypoglycemia and normoxia/normoglycemia $(\mathrm{H} / \mathrm{H}-\mathrm{N} / \mathrm{N})$. We observed increased expression of type 1 IFN-stimulated genes (ISGs) as the predominant transcriptomal feature of $\mathrm{H} / \mathrm{H}-\mathrm{N} / \mathrm{N}$-exposed WT, but not $T L R 4^{-1-}$, microglia. Microarray analysis on ex vivo sorted microglia from ipsilateral male mouse cortex after a transient in vivo ischemic pulse also demonstrated robust expression of ISGs. Type 1 IFNs, including the IFN- $\alpha$ s and IFN- $\beta$, activate the interferon- $\alpha / \beta$ receptor (IFNAR) complex. We confirmed both in vitro $\mathrm{H} / \mathrm{H}-\mathrm{N} / \mathrm{N}$ - and in vivo ischemia/reperfusion-induced microglial ISG responses by quantitative real-time PCR and demonstrated that both were dependent on IFNAR1. We characterized the effects of hypoxia/hypoglycemia on phosphorylation of signal transducer and activator of transcription 1 (STAT1), release of type 1 IFNs, and surface expression of IFNAR1 in microglia. We demonstrated that IFN- $\beta$ induces dose-dependent secretion of ISG chemokines in cultured microglia and robust ISG expression in microglia both in vitro and in vivo. Finally, we demonstrated that the microglial ISG chemokine responses to TLR4 agonists were dependent on TLR4 and IFNAR1. Together, these data suggest novel ischemia/reperfusion-induced pathways for both TLR4-dependent and -independent, IFNAR1-dependent, type 1 IFN signaling in microglia.

Key words: hypoxia; interferons; ischemia; microglia; reperfusion

Significance Statement

Stroke is the fifth leading cause of death in the United States and is a leading cause of serious long-term disability worldwide. Innate immune responses are critical in stroke pathophysiology, and microglia are key cellular effectors in the CNS response to ischemia/ reperfusion. Using a transcriptional analysis approach, we identified a robust interferon (IFN)-stimulated gene response within microglia exposed to ischemia/reperfusion in both in vitro and in vivo experimental paradigms. Using a number of complementary techniques, we have demonstrated that these responses are dependent on innate immune signaling components including Toll-like receptor-4 and type I IFNs. We have also elucidated several novel ischemia/reperfusion-induced microglial signaling mechanisms.

\section{Introduction}

Stroke accounts for more than half of all patients hospitalized for acute neurological disease in the United States and is the second

Received March 16, 2017; revised July 14, 2017; accepted July 20, 2017.

Author contributions: S.M., T.M., and J.R.W. designed research; A.M., R.V.L., S.N., C.L., T.L., M.I., J.L.H.P., and J.R.W. performed research; A.M., R.V.L., S.N., C.L., T.L., M.I., J.L.H.P., S.M., and J.R.W. analyzed data; A.M. and J.R.W. wrote the paper.

This work was supported by the National Institute of Neurological Disorders and Stroke-National Institutes of Health (Grants NS065008 and NS076620 to J.R.W. and Grant NS100245 to A.M.). We thank Anna Conti, Jamie Colman, Diana Chao, and Rona Lee for assistance with the middle cerebral artery occlusion surgery; Theo Bammler, Richard P. Beyer, and Michael Coon at the University of Washington (UW) Functional Genomics and Proteomics Core for excellent technical assistance with processing our microarrays and bioinformatics analysis; and the UW Center on Human Development and Disability for their support of our genomics work.

The authors declare no competing financial interests. most common cause of death worldwide (Mohr et al., 2010). Microglia, the resident immune cells in the CNS, play a major role in the neuroinflammatory response in many neurological diseases, including stroke (Benarroch, 2013). Although microglial activation was once considered to be a relentlessly proinflammatory process, it is now clear that microglia can also enhance and accelerate neural cell recovery and regeneration (Hanisch and Kettenmann, 2007; Kettenmann et al., 2011; Michell-Robinson et al., 2015). De-

\footnotetext{
*A.M. and R.V.L. contributed equally to this work.

Correspondence should be addressed to Jonathan R. Weinstein, Department of Neurology, University of Washington, Box 356465, 1959 NE Pacific Street, Seattle, WA 98195. E-mail: jweinste@u.washington.edu. DOI:10.1523/JNEUROSCI.0725-17.2017

Copyright $\odot 2017$ the authors $\quad 0270-6474 / 17 / 378292-17 \$ 15.00 / 0$
} 
spite their central role in stroke pathophysiology, there is little mechanistic information available on the effects of ischemia/reperfusion on microglial gene expression and phenotype (Crotti and Ransohoff, 2016).

Toll-like receptors (TLRs) are a family of pattern recognition receptors involved in the immune response to pathogens (Janeway et al., 2005). Activation of TLRs by endogenous ligands, also known as danger-associated molecular patterns (DAMPs), released from ischemic tissue initiates the inflammatory response in stroke (Karikó et al., 2004). A number of putative DAMPs have been identified in brain, including heat shock proteins (Lehnardt et al., 2008), high-mobility group box 1 (HMGB1) (Muhammad et al., 2008; Laird et al., 2014), and peroxiredoxins (Shichita et al., 2012a), which are all endogenous activators of TLR4. TLR4 signaling has been implicated in neuroinflammation (Lehnardt, 2010), stroke pathophysiology (Caso et al., 2007), and ischemic preconditioning (IPC) (Pradillo et al., 2009; Hamner et al., 2015). Microglia express high levels of TLR4, and TLR4 agonists activate microglia potently (Olson and Miller, 2004; Holm et al., 2012; Scheffel et al., 2012). To determine how microglial TLR4 contributes to the ischemia/reperfusion response in brain, we previously performed and reported (Weinstein et al., 2010) results of microarray and bioinformatic gene set enrichment analyses on primary microglia derived from either WT or TLR4 ${ }^{-1-}$ mice after exposure to $24 \mathrm{~h}$ of either hypoxia/hypoglycemia ("ischemialike") or normoxia/normoglycemia ("control") conditions followed by $24 \mathrm{~h}$ of normoxia/normoglycemia ("reperfusion-like") conditions (Fig. 1A). These data and analyses demonstrated that exposure to ischemia/reperfusion-like conditions induced numerous and robust changes in the transcriptome of WT microglia, which was markedly disparate from the response of TLR4 ${ }^{-1-}$ microglia and suggested a fundamental role for TLR4 in determining the microglial response to ischemia/reperfusion (Weinstein et al., 2010).

Here, we present new results from a higher stringency analysis of the individual gene expression data, as well as a transcription factor (TF)-binding analysis, from the genomic dataset discussed above. These analyses identified type 1 interferon (IFN)-stimulated genes (ISGs) as the predominant transcriptional activation feature of $\mathrm{H} / \mathrm{H}-\mathrm{N} / \mathrm{N}$-exposed $\mathrm{WT}$, but not TLR4 ${ }^{-1-}$, microglia. Type 1 IFNs are a multigene cytokine family than includes 14 IFN- $\alpha$ subtypes and a single IFN- $\beta$ (McNab et al., 2015). The type I IFNs are best known for their ability to induce an antiviral state in both infected and bystander cells (Ivashkiv and Donlin, 2014; $\mathrm{McNab}$ et al., 2015). However, recent studies have implicated them as key regulators of the neuroimmune response triggered by noninfectious causes of CNS injury (Prinz et al., 2008; Khorooshi and Owens, 2010; Brendecke and Prinz, 2012; Owens et al., 2014) and type I IFNs are implicated in experimental neuroprotective phenomena such as lipopolysaccharide (LPS) (Marsh et al., 2009) and ischemic (Stevens et al., 2011; Hamner et al., 2015) preconditioning. In the current study, we confirm the microglial ISG response to ischemia/reperfusion-like conditions in vitro and explore key aspects of the molecular mechanisms involved. Furthermore, we present complementary in vivo data demonstrating that transient ischemia followed by reperfusion in mice induces broad and robust ISG expression in acutely isolated, ex vivo sorted cortical microglia. We then characterize the dependence of this in vivo microglial response on interferon- $\alpha / \beta$ receptor 1 (IFNAR1) and TLR4. Based on our findings, we propose several molecular signaling pathways that underlie ischemia/reperfusion-induced microglial ISG expression and type 1 IFN signaling.

\section{Materials and Methods}

Solutions and reagents. Recombinant mouse granulocyte-macrophage colony stimulating factor (GM-CSF) and IFN- $\beta$ were purchased from R\&D Systems. Polyinosinic-polycytidylic acid was obtained from InvivoGen. All solutions were freshly prepared from frozen stock solutions or lyophilized preparations. All materials were handled in a sterile manner using endotoxin-free microfuge tubes (Eppendorf; Fisher Scientific), polypropylene tubes (Becton Dickinson Labware), polystyrene culture vessels (Becton Dickinson Labware), serological pipettes (Corning), precision pipette tips (Rainin Instruments), water (Associates of Cape Cod), and PBS (Invitrogen).

Cell culture. Primary microglia were prepared from the cortex of mixed sex neonatal [postnatal day 4 (P4) or P5] C57BL/6J WT, TLR4 ${ }^{-1-}$ (Hoshino et al., 1999), or IFNAR1 ${ }^{-1-}$ (Müller et al., 1994) mice as described previously (Giulian and Baker, 1986; Möller et al., 2000). In brief, cortical tissue was carefully dissected from blood vessels and meninges, digested with $50 \mathrm{ng} / \mathrm{ml}$ DNase, triturated, and washed. Cortical cells were cultured in DMEM (Invitrogen) supplemented with $10 \%$ heat inactivated fetal bovine serum (FBS) (Hyclone) and penicillin/streptomycin (P/S), (50 $\mathrm{IU} / \mathrm{ml}$ and $50 \mu \mathrm{g} / \mathrm{ml}$, respectively; Mediatech/Corning) plus $2 \mathrm{ng} / \mathrm{ml}$ GM-CSF (R\&D Systems) for 10-21 d (media change every 3-4 d). Microglia were separated from the underlying astrocytic monolayer by gentle agitation and centrifuged $(100 \times g$ for $10 \mathrm{~min})$. The cell pellet was resuspended in DMEM/10\% FBS with P/S plus $2 \mathrm{ng} / \mathrm{ml} \mathrm{GM-CSF}$ and plated on Primaria culture dishes and plates (Falcon) at a density of $2 \times$ $10^{5}$ cells per well in 24 well plates for gene expression, cell viability, and flow cytometry studies or $5 \times 10^{4}$ cells per well in 96 well plates for ELISA studies. Nonadherent cells were removed 30-60 min after plating by changing the medium and adherent microglia were incubated for $24 \mathrm{~h}$ in culture medium. We confirmed purity of our primary microglia population by flow cytometry based on their expression of CD11b (>96\% of total cell population).

Hypoxia/hypoglycemia followed by normoxia/normoglycemia $(\mathrm{H} / \mathrm{H}-$ $N / N)$ paradigm. We have demonstrated previously that $1 \%$ oxygen combined with moderate hypoglycemia (250 $\mu \mathrm{M}$ glucose) induces marked increases in both intracellular hypoxia inducible factor-1 (HIF-1) levels and HIF-1 target gene expression in primary microglia (Weinstein et al., 2010). For the current study, microglia were serum starved for $24 \mathrm{~h}$ in DMEM (high glucose $4.5 \mathrm{~g} / \mathrm{L}$ or $25 \mathrm{~mm}$ ) with $1 \times$ insulin/transferrin/ selenium-G supplement (Invitrogen) and albuMAX I ( $1 \mathrm{mg} / \mathrm{ml}$ ) (Invitrogen). We will refer to the above prepared solution as serum-free medium-normoxia/normoglycemia (SFM-N/N). Next, microglia were treated for $24 \mathrm{~h}$ in either SFM-N/N in normoxic $\left(21 \% \mathrm{O}_{2}\right)$ control conditions or SFM containing glucose-free DMEM supplemented with 250 $\mu \mathrm{M}$ glucose plus $25 \mathrm{~mm}$ nonmetabolizable sucrose (to control for osmolarity) in hypoxic $\left(1 \% \mathrm{O}_{2}\right)$ conditions (SFM-hypoxia/hypoglycemia or $\mathrm{SFM}-\mathrm{H} / \mathrm{H})$. The latter was used to mimic "ischemia-like" conditions. Finally, cells were cultured for $24 \mathrm{~h}$ in SFM-N/N medium and normoxic $\left(21 \% \mathrm{O}_{2}\right)$ control conditions to mimic "reperfusion-like" conditions (Fig. 1A). We will refer to this entire experimental paradigm as hypoxia/ hypoglycemia followed by normoxia/normoglycemia or $\mathrm{H} / \mathrm{H}-\mathrm{N} / \mathrm{N}$ throughout. Our lactate dehydrogenase (LDH) release (Fig. $1 B, C$ ) and Trypan blue dye exclusion (Fig. $1 D$ ) data indicate that the moderate degree of hypoxia/hypoglycemia used in our $\mathrm{H} / \mathrm{H}-\mathrm{N} / \mathrm{N}$ model induced a relatively small amount of cell death and that cell viability stabilized after restoration of normoxic/normoglycemic conditions.

Cell viability assays. Released LDH activity is a stable enzymatic marker that correlates with cell death (Koh and Choi, 1987). To further characterize the effects of our $\mathrm{H} / \mathrm{H}-\mathrm{N} / \mathrm{N}$ paradigm on the basic properties of cultured primary microglia, we performed LDH release assays on conditioned medium at two time points: immediately after $24 \mathrm{~h}$ of hypoxic/ hypoglycemic exposure (time point $a$ ) and immediately after the ensuing $24 \mathrm{~h}$ normoxic/normoglycemic exposure (time point $b$ ) (Fig. 1A). An enzymatic assay was used to measure cytoplasmic LDH released into the medium using the $\mathrm{LDH}$ kit according to the manufacturer's instructions (Sigma-Aldrich). In brief, the medium of each well was collected and added to a 96-well plate and incubated for $30 \mathrm{~min}$ at room temperature with the substrate mixture provided with the kit to detect LDH activity. A 
A

\section{in vitro hypoxia/hypoglycemia-normoxia/normoglycemia paradigm}
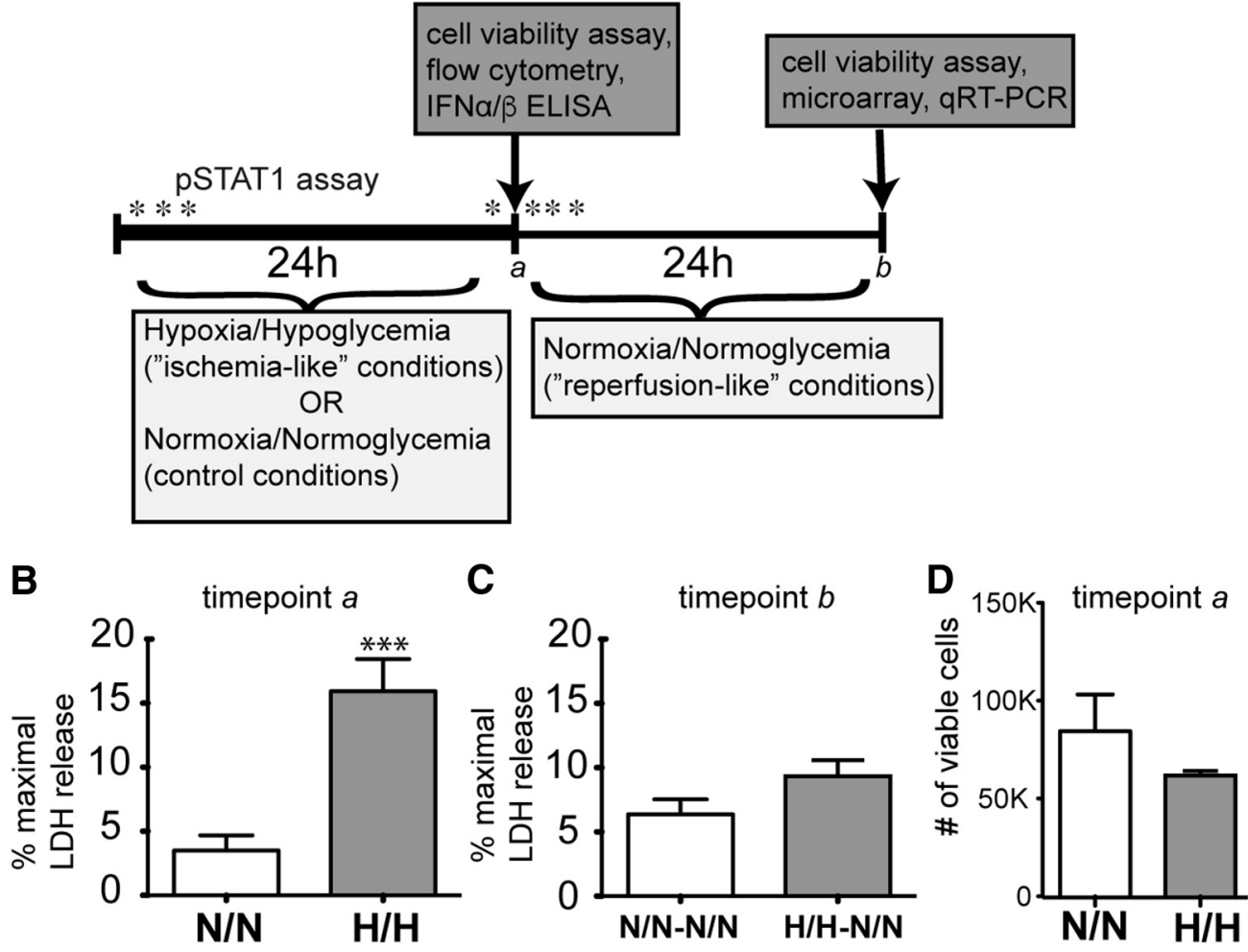

E in vivo paradigm 12-14 week old mice

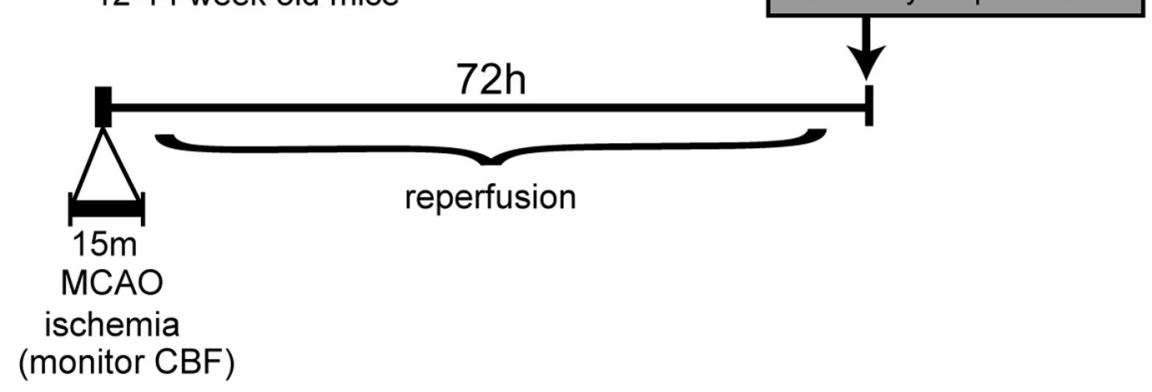

Figure 1. Experimental paradigms for in vitro $\mathrm{H} / \mathrm{H}-\mathrm{N} / \mathrm{N}$ and in vivo ischemia/reperfusion studies. $A, \mathrm{WT}, \mathrm{TLR4^{-1 }}{ }^{-}$, or IFNAR1 $1^{-1-}$ primary microglia are exposed to $\mathrm{H} / \mathrm{H}$ (ischemia-like) or $\mathrm{N} / \mathrm{N}$ (control) conditions for $24 \mathrm{~h}$ (time point $a$ ) and then subsequently exposed to normoxia/normoglycemia (reperfusion-like) conditions for an additional $24 \mathrm{~h}$ (time point $b$ ). Cell viability assays including quantification of LDH levels were performed at both time points $a$ and $b$, whereas Trypan blue exclusion microscopy-based cell counting was performed at time point $a$ only. RNA extraction followed by microarray analysis or qRT-PCR was performed at time point $b$ only. Flow cytometry studies to quantify cell surface expression of IFNAR1 and high-sensitivity ELISAs for IFN- $\alpha$ and IFN- $\beta$ were performed at time point $a$ only. Assays quantifying the level of phosphorylation of STAT1 were performed at multiple time points indicated by the asterisks. $\boldsymbol{B}-\boldsymbol{D}$, Assessment of microglial viability in culture after exposure to the indicated conditions. Normalized release of $\mathrm{LDH}$ into conditioned medium from microglia after exposure to: $\mathrm{H} / \mathrm{H}$ or N/N for $24 \mathrm{~h}$ (time point $a ; p=0.0002$, unpaired $t$ test, $\mathrm{N}=9$ separate microglial samples for each experimental group and genotype processed in three separate experiments, respectively; $\boldsymbol{B}$ ) or either $\mathrm{N} / \mathrm{N}$ or $\mathrm{H} / \mathrm{H}$ for $24 \mathrm{~h}$ followed by $\mathrm{N} / \mathrm{N}$ for $24 \mathrm{~h}$ (time point $b ; p=0.0969$, unpaired $t$ test, $n=9$ separate microglial samples for each experimental group and genotype processed in three separate experiments, respectively; $\boldsymbol{C}$. D, Number of viable cells as determined by Trypan blue exclusion assay after exposure to $\mathrm{H} / \mathrm{H}$ or $\mathrm{N} / \mathrm{N}$ for $24 \mathrm{~h}$ (time point $a ; p=0.2988$, unpaired $t$ test, $n=3$ separate microglial samples processed in three

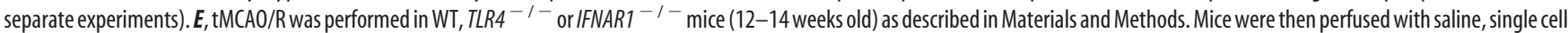
suspensions were prepared from ipsilateral and contralateral cortex, and microglia were isolated using ex vivo flow cytometry as described in Materials and Methods. RNA was then isolated from the sorted microglia and processed for microarray or qRT-PCR as described in Materials and Methods.

stop solution $(1 \mathrm{~N} \mathrm{HCl})$ was added and the absorbance of the sample was measured at $490 \mathrm{~nm}$ in a microplate reader. Each sample was tested three times and an average value was recorded. One well (treated with normoxic/normoglycemic conditions) was lysed by incubating with the kit lysis solution for $45 \mathrm{~min}$ to obtain a measure of total LDH. The amount of $\mathrm{LDH}$ released into the culture medium was expressed as the percentage of total LDH release. We found that WT primary microglia exposed to hypoxic/hypoglycemic conditions for $24 \mathrm{~h}$ (Fig. $1 A$, time point $a$ ) showed more $\mathrm{LDH}$ release (a surrogate marker for cell death) than those exposed to normoxia/normoglycemia control conditions ( $16 \pm 3 \%$ vs $4 \pm 1 \%$, $t=4.617, p=0.0002$; unpaired $t$ test; Fig. $1 B)$ at the same time point. However, after medium change and an additional $24 \mathrm{~h}$ in normoxia/ 
normoglycemia (reperfusion-like) conditions (Fig. $1 A$, time point $b$ ), $\mathrm{LDH}$ release levels returned to baseline $(9 \pm 1 \%$ vs $6 \pm 1 \%, t=1.763, p=$ 0.0969 , unpaired $t$ test) (Fig. 1C). Trypan blue exclusion assay is another well described method for quantifying cell viability (Cadena-Herrera et al., 2015). To confirm our LDH assay findings, we collected microglia exposed to $24 \mathrm{~h}$ of hypoxia/hypoglycemia (Fig. $1 \mathrm{~A}$, time point $a$ ) and performed direct cell counting of viable (refractile appearing, Trypan blue negative) microglia using phase-contrast microscopy. We observed a mild decrease in cell viability after exposure to $24 \mathrm{~h}$ of hypoxia/hypoglycemia that was not significant $(t=1.193, p=0.2988$, unpaired $t$ test; Fig. $1 D)$.

In vivo model of transient ischemia/reperfusion and ex vivo flow cytometry. Transient (15 min) middle cerebral artery occlusion followed by $72 \mathrm{~h}$ reperfusion ( $\mathrm{tMCAO} / \mathrm{R}$ ) or sham surgery was performed under isoflurane inhalational anesthesia on 12- to 14-week-old male WT, TLR4 ${ }^{-1-}$ (Hoshino et al., 1999), or IFNAR1 ${ }^{-1-}$ (Müller et al., 1994) mice using the transient intraluminal filament method (Longa et al., 1989) with laser Doppler flowmetry for monitoring of cerebral blood flow (CBF) as we have described previously (Su et al., 2014; McDonough and Weinstein, 2016). We excluded mice with $<70 \%$ reduction in $\mathrm{CBF}$ from further processing. After tMCAO, the filament was removed and MCA reperfusion was confirmed by laser Doppler. Incisions were sutured closed and mice were allowed to recover with full vascular reperfusion for $72 \mathrm{~h}$ (Su et al., 2014; McDonough and Weinstein, 2016; Fig. $1 E)$. Mice were then deeply anesthetized with intraperitoneal sodium pentobarbital and perfused intracardially with ice-cold calcium- and magnesium-free Hank's balanced salt solution (HBSS; Invitrogen) containing 1 mM HEPES. Ipsilateral and contralateral or sham-operated cortices were dissected out separately and then mechanically and enzymatically dissociated as described previously (Su et al., 2014; McDonough and Weinstein, 2016). Depletion of myelin and positive selection of myeloid cells with CD11b microbead column (Miltenyi Biotec) were performed as described previously (Su et al., 2014; McDonough and Weinstein, 2016). The myeloid-enriched cell suspension was stained with a panel of fluorochrome conjugated antibodies (BD PharMingen; eBioscience; Fisher Scientific) against microglia, macrophage, and neutrophil markers and 2-(4-amidinophenyl)-6-indolecarbamidine dihydrochloride (DAPI; Sigma-Aldrich) and flow cytometrically sorted on a BD Biosciences FACSAria II cell sorter directly into TRIzol LS reagent (Invitrogen). Microglia were defined as the population of live (DAPI ${ }^{\text {negative }}$ ) cells that were Ly6C ${ }^{\text {negative }}$, Ly6 $6 \mathrm{G}^{\text {negative }}, \mathrm{F} 4 / 80^{\text {positive }}, \mathrm{CD} 45^{\text {low/intermediate }}$ as we have described previously (McDonough and Weinstein, 2016). Cellular identity of sorted cortical microglia was confirmed by our transcriptional analysis on extracted microglial RNA showing high levels of expression ( $>95 \%$ of all genes in microarray) for multiple known microglia-specific genes (Butovsky et al., 2014), including P2ry12, Fcrls, Tmem119, Hexb, and Tgfbrl in both naive and ischemia/reperfusionexposed WT mice. It is important to note that our tMCAO/R model is a unilateral insult and allows for an internal control in ex vivo studies: the contralateral cortex. An important advantage of using contralateral controls is that they eliminate a key source of biological variability because ipsilateral and contralateral samples are all drawn from the same animals, isolated in parallel, and subjected to the same conditions of mechanical and enzymatic digestion. Therefore, cellular changes in gene expression that may occur in the process of microglial isolation are reflected in both control and ischemia/reperfusion hemispheres of the brain and should not confound true in situ biological changes induced by ischemia/reperfusion.

Intracerebroventricular injection of IFN- $\beta$. Mice (12- to 14 -week-old males) were anesthetized with $4 \%$ isoflurane to induce, and $2 \%$ to maintain, the surgical plane. The mouse heads were immobilized within a stereotaxic frame in flat skull position and a $1 \mathrm{~cm}$ midsagittal skin incision was made on the scalp to expose the skull. The coordinates for the lateral ventricle location were determined based on the Paxinos and Franklin adult mouse brain atlas. A hole was drilled through the skull at the appropriate coordinates $(-0.9 \mathrm{~mm}$ anteroposterior, $1.4 \mathrm{~mm}$ lateral to the bregma, and $2.0 \mathrm{~mm}$ from the skull surface) and a needle was advanced stereotaxically so that the internal tip was located within the right lateral ventricle. The solution of either $2000 \mathrm{U}$ recombinant mouse IFN- $\beta$ (R\&D Systems) or sterile saline vehicle was injected in a volume of $2 \mu \mathrm{l}$ over a period of $2 \mathrm{~min}$. The needle was kept at the site for an additional $5 \mathrm{~min}$ before being slowly withdrawn to prevent back flow. Twenty-four hours after injection of either IFN- $\beta$ or vehicle, the mice were killed and their brains collected as above for ex vivo flow cytometric sorting of microglia.

Microarray analysis. For both in vitro and in vivo studies, microglial RNA was extracted, analyzed, and processed for hybridization to Mouse Gene 1.0 ST Arrays (Affymetrix) as described previously (Anderson et al., 2011). Raw data were processed, normalized, and analyzed as described previously (Smyth, 2004; Wu et al., 2004; Weinstein et al., 2010). For in vitro studies, individual genes with evidence of significant differential expression between strains (WT vs TLR $4^{-1-}$ ) and/or conditions $(\mathrm{H} / \mathrm{H}-$ $\mathrm{N} / \mathrm{N}$ vs control) were identified by fitting an ANOVA model to the data using the Bioconductor limma package (Ritchie et al., 2015) and then computing empirical Bayes-adjusted contrasts (Phipson et al., 2016). We selected genes based on an unadjusted $p<0.05$ as well as a 2.0-fold (for in vitro dataset) difference in expression, based on the recommendations of the MAQC consortium (Shi et al., 2006). Comparisons showing distinct and overlapping subsets of significantly regulated ( $>2$-fold) individual genes are presented as a Venn diagram (Fig. 2A). We performed bioinformatic TF-binding site (TFBS)/promoter analysis on the regulatory regions of the $\mathrm{H} / \mathrm{H}-\mathrm{N} / \mathrm{N}$-regulated genes in the WT microglia. TFBSs were predicted using Pscan (Zambelli et al., 2009), a web-based tool that compares the promoter regions of user-supplied lists of transcripts against known TFBS sequences and calculates a genome-wide background score for each TFBS and a $Z$-score for each TF. Each TF is then ranked by their $Z$-score, which indicates the likelihood that one or more consensus binding sites for a particular TF is more frequent in the promoters of user-supplied transcripts than in the genome background. For our in vivo microarray data (see Table 3), we selected genes based on an unadjusted $p<0.05$ as well as a 1.5 -fold difference in expression (Shi et al., 2006). We calculated adjusted $p$-values to take into account the false discovery rate in the setting of multiple comparisons.

Reverse transcription and quantitative real-time PCR. To detect mRNA expression of a panel of ISGs in mouse primary microglia, RNA was first isolated using the RNeasy Micro kit (Qiagen) with on-column DNase digestion. For in vitro IFN- $\beta$-stimulated microglia, the mouse IFN- $\alpha, \beta$ Response RT ${ }^{2}$ Profiler PCR Array (Qiagen; catalog \#330231 PAMM016 ) was used. RNA (600 ng) was reverse transcribed into cDNA using the $\mathrm{RT}^{2}$ First Strand cDNA Synthesis kit (Qiagen) including genomic DNA elimination step per manufacturer's protocol. Quantitative realtime PCR (qRT-PCR) was then performed on a StepOnePlus real-time PCR system (Applied Biosystems) using the RT ${ }^{2}$ SYBR Green ROX reference dye qPCR Mastermix (Qiagen) under the following cycling parameters: $95^{\circ} \mathrm{C}$ for $10 \mathrm{~min}$ for 40 cycles, with each cycle consisting of $95^{\circ} \mathrm{C}$ for $15 \mathrm{~s}$ and $60^{\circ} \mathrm{C}$ for $1 \mathrm{~min}$. A subsequent melt curve step was performed to verify single-species PCR product.

For primary microglia exposed in vitro to $\mathrm{H} / \mathrm{H}-\mathrm{N} / \mathrm{N}$ or control conditions and for ex vivo sorted cortical microglia from both ipsilateral and contralateral mouse brain $72 \mathrm{~h}$ after tMCAO/R or $24 \mathrm{~h}$ after ICV injection of IFN- $\beta$, custom PrimePCR Assay plates (Bio-Rad) were used that contained a selection of ISG target genes along with three chosen housekeeping genes ( $h p r t, y w h a z$, and sdha). RNA (250 ng) was reverse transcribed into cDNA using the iScript Reverse Transcription Supermix (Bio-Rad). qRT-PCR was then performed using the SsoAdvanced SYBR Green Supermix (Bio-Rad), along with the appropriate controls, per the manufacturer's protocol. PCR cycling conditions were performed as follows: $95^{\circ} \mathrm{C}$ for $30 \mathrm{~s}$ for 40 cycles, with each cycle consisting of $95^{\circ} \mathrm{C}$ for $10 \mathrm{~s}$ and $60^{\circ} \mathrm{C}$ for $30 \mathrm{~s}$. Melt curve analysis was performed thereafter.

Data were analyzed using Sequence Detection Software version 1.3 (Applied Biosystems) as described previously (Quan et al., 2009) and with PRISM software (GraphPad). Relative fold changes were calculated using the delta-delta $\mathrm{Ct}$ method. For fold changes less than unity, values were converted to their negative inverse to obtain the fold downregulation.

ELISAs for secreted chemokines and cytokines. ELISAs were performed as described previously (Weinstein et al., 2005). In brief, microglia were plated in 96-well plates in DMEM with $10 \%$ FBS and, after $24 \mathrm{~h}$, cells were washed once with PBS and cultured ("serum starved") in SFM-N/N for additional $24 \mathrm{~h}$ before stimulation with indicated dosages of either 
A

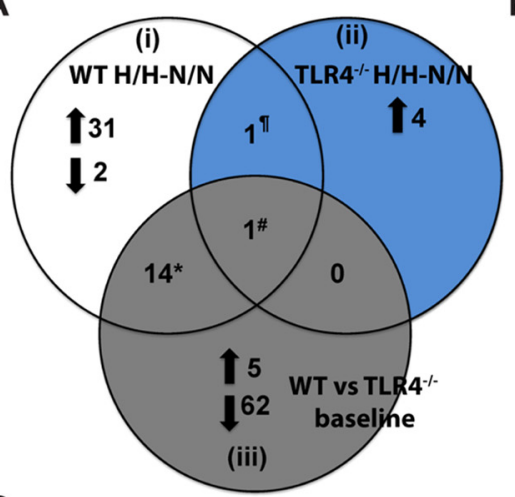

C
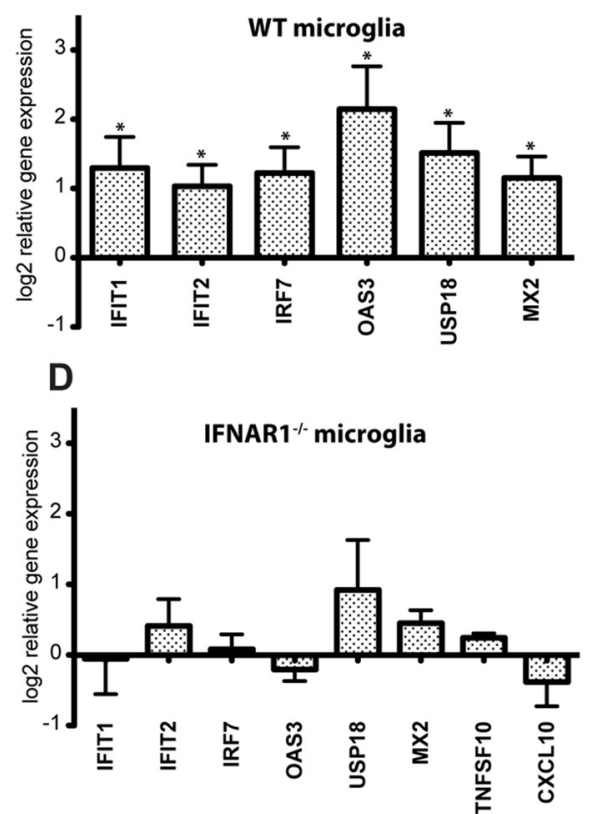

B

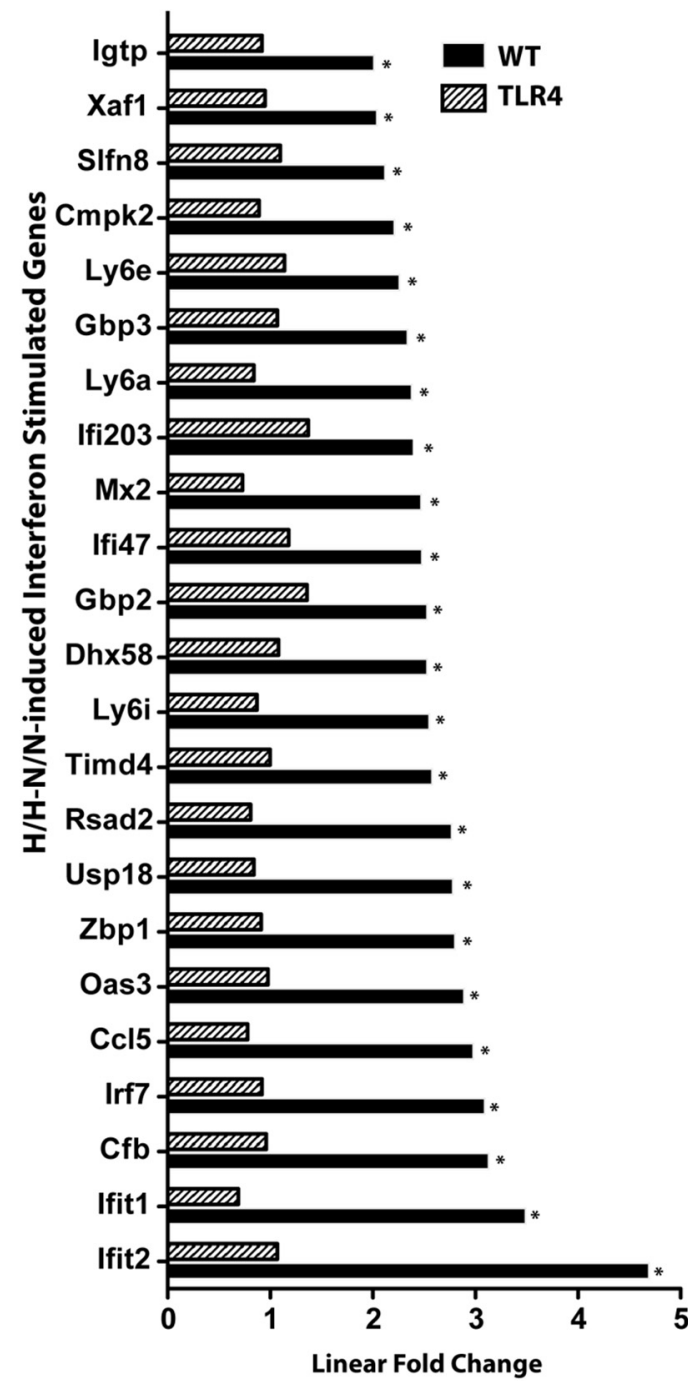

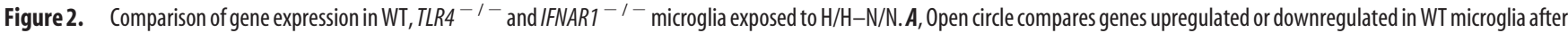
$\mathrm{H} / \mathrm{H}-\mathrm{N} / \mathrm{N}$ relative to control conditions; the blue circle compares genes upregulated or downregulated in $T L R 4^{-1}$ - microglia after $\mathrm{H} / \mathrm{H}-\mathrm{N} / \mathrm{N}$ relative to control conditions; and the gray circle compares differences in baseline expression of genes between the WT and TLR4 ${ }^{-1-}$ controls. We observed marked differences in gene expression between all three comparisons and little overlap in transcriptional profiles between the different transgenic microglia and culture conditions. १This gene (S/co4a1) was downregulated by H/H-N/N in both the WT and TLR4 ${ }^{-1-}$ microglia. \#This gene (Pirra) was upregulated by $\mathrm{H} / \mathrm{H}-\mathrm{N} / \mathrm{N}$ in both the WT and $\mathrm{TLR} 4^{-1-}$ microglia but was downregulated in the $\mathrm{TLR}^{-1-}$ microglia relative to the WT microglia under control conditions. *All 14 of these genes were upregulated in the WT microglia exposed to $\mathrm{H} / \mathrm{H}-\mathrm{N} / \mathrm{N}$, whereas all 14 of these same genes were downregulated in the $T L R 4^{-1-}$ microglia relative to the WT microglia under control conditions. $n=12$ separate microglial samples for each experimental group and genotype processed in four separate experiments. $\boldsymbol{B}$, Microarray data showing relative normalized gene expression levels for a panel of ISGs in primary microglia derived from either WT or TLR4 ${ }^{-1-}$ mice that had been exposed to $\mathrm{H} / \mathrm{H}$ (ischemia-like) or N/N (control) conditions for $24 \mathrm{~h}$ and then subsequently exposed to N/N (reperfusion-like) conditions for an additional $24 \mathrm{~h}$ (time point $b$ in Fig. 1A). RNA was extracted and microarray was performed and analyzed as described in the Materials and Methods. ${ }^{*} p<0.05$ comparing $\mathrm{H} / \mathrm{H}-\mathrm{N} / \mathrm{N}$ vs N/N-N/N conditions for each of the $23 \mathrm{ISGs}$ upregulated $>2$-fold that were identified in the WT microglia (Table 1 ). $\mathrm{N}=12$ separate microglial samples $\left(\sim 2 \times 10^{5}\right.$ cells per well) for each experimental group and genotype processed in four separate experiments. Data were analyzed by ANOVA, with individual p values reported in Table 1 . C-D, qRT-PCR data showing relative normalized gene expression levels for a panel of ISGs in either WT (C) or IFNAR1 ${ }^{-1-}$ (D) primary microglia that had been exposed to H/H (ischemia-like) or N/N (control) conditions for $24 \mathrm{~h}$ and then subsequently exposed to $\mathrm{N} / \mathrm{N}$ (reperfusion-like) conditions for an additional $24 \mathrm{~h}$ ( $\mathrm{H} / \mathrm{H}-\mathrm{N} / \mathrm{N}$; time point $b$ in Fig. 1A). C, $p$-values (unpaired $t$ test) are as follows for WT microglia exposed to H/H-N/N: ifit1, $p=0.0291 ;$ ifit2, $p=0.0189 ;$ irf7, $p=0.0194 ;$ oas3, $p=0.0163 ;$ usp 18, $p=0.0165$; and $m \times 2, p=0.0143$. D, $p$-values (unpaired $t$ test) are as follows for IFNAR1 ${ }^{-1}{ }^{-}$microglia exposed to $\mathrm{H} / \mathrm{H}-\mathrm{N} / \mathrm{N}:$ ifit $1, p=0.1211 ;$ ifit2, $p=0.4527 ;$ irf7, $p=0.3856 ;$ oas $3, p=0.2283 ;$ usp $18, p=0.4610 ; m \times 2, p=0.0971 ;$ tnsf10, $p=0.6449 ;$ and cxcl10, $p=$ 0.2905. Expression data were normalized to a panel of housekeeping genes and presented as relative to expression in microglia exposed to N/N for $24 \mathrm{~h}$ followed by N/N control conditions for additional $24 \mathrm{~h}(\mathrm{~N} / \mathrm{N}-\mathrm{N} / \mathrm{N}) .{ }^{*} p<0.05$ comparing ischemia-like/reperfusion-like versus control/reperfusion-like conditions for each ISG. $n=9$ separate microglial samples for each experimental group and genotype processed in three separate experiments.

IFN- $\beta$, LPS (Associates of Cape Cod), human recombinant heat shock protein 70 (HSP70; Bio Vision), or $\mathrm{H} / \mathrm{H}-\mathrm{N} / \mathrm{N}$ for the indicated time periods. Quantification of chemokines CXCL10 and CCL5 was performed using mouse-specific antibody pairs and mouse protein standards designed for ELISA application (R\&D Systems). Quantification of IFN- $\beta$ was performed using the LEGEND MAX mouse IFN- $\beta$ ELISA kit (BioLegend). Quantification of IFN- $\alpha$ was performed using VeriKine mouse IFN- $\alpha$ ELISA kit (PBL Interferon Source). All experiments were performed in accordance with manufacturer's instructions with a mini- mum of 12 wells per condition $(n \geq 12)$ and a minimum of three independent experiments.

Flow cytometry-based assays for expression of surface receptors and phosphorylation of signal transducer and activator of transcription 1 (STAT1). After IFN- $\beta$ stimulation or hypoxia/hypoglycemia treatment, primary microglia were detached from 24-well plates in ice-cold 2 mм EDTA/ PBS. Cells were then washed with FACS medium (HBSS containing 10\% FBS and 10 mM HEPES) and incubated with Fc block (BD PharMingen) for $5 \mathrm{~min}$ on ice. Primary microglia were then stained with DAPI (Sigma- 
Aldrich) and separately with one of the following fluorochrome-conjugated antibodies: anti-mouse-CD45 (BD PharMingen); anti-mouse-F4/80, antimouse-CD11b, or anti-mouse-TLR4 (eBioscience); or anti-mouseIFNAR1 or anti-mouse-CD64 (Fc $\gamma$ R1; BioLegend) for $60 \mathrm{~min}$ on ice. After antibody staining, cells were washed and resuspended in $250 \mu \mathrm{l}$ of FACS medium. To assess phosphorylation of STAT1 quantitatively, after stimulation and cell collection as above, microglia were fixed in $4 \%$ paraformaldehyde for $15 \mathrm{~min}$, washed with PBS, and then permeabilized in Perm/Wash buffer (BD Biosciences) for $15 \mathrm{~min}$. Cells were then washed again and stained with fluorochrome-conjugated mouse anti-pSTAT1 (pY701) or isotype control antibodies (BD Biosciences) for $45 \mathrm{~min}$ at $4^{\circ} \mathrm{C}$ in stain buffer (BD Biosciences) and then washed twice. Data acquisition and analysis were performed using the BD Biosciences FACSCanto II flow cytometer and FlowJo software (TreeStar). Numerical data for surface antigen expression are given as the mean \pm SEM of the normalized specific binding median values from each independent experiment. For pSTAT1 assays, we show the percentage of events in the pSTAT1-positive gate in unstimulated or stimulated cells stained with the anti-pSTAT1 antibody (a baseline value of $\leq 2.5 \%$ positive events was set by gating using unstimulated cells stained with isotype control antibody). Numerical data for PSTAT1 assays indicate mean \pm SEM of the positive events normalized to either unstimulated or IFN- $\beta$-stimulated cells as indicated. All experiments were performed in triplicate unless otherwise indicated.

Experimental design and statistical analysis. Statistical evaluation was performed using PRISM version 5.0 software (GraphPad). Comparisons between multiple experimental groups were made using one or two-way ANOVA with Bonferroni's or Dunnett's post test as appropriate. For comparisons between a single experimental group and a control group, we used Student's $t$ test. $p<0.05$ was considered to be significant. Data are given as mean \pm SEM. Details on statistical analyses and experimental design, including which tests were performed, $F$ and/or $t$ values as appropriate, exact $p$-values (within resolution of software limits), sample sizes $(N)$, and replicates, are provided within the Results section describing each figure or within the legend of each figure. Data tables reporting the fold regulation also include separate columns for both raw and adjusted $p$-values, with experimental conditions and replicates included to facilitate reproducibility of data.

The number of animals used in each experiment (indicated in the Materials and Methods, in the Results describing each figure, and/or in the figure legends) was determined using a modified power analysis with improved stopping rules for the design of efficient small sample experiments (Fitts, 2010). This analysis identified a range (minimum to maximum) for the number of animals per experimental group sufficient to achieve a statistically significant difference ( $p<0.05,90 \%$ power) between the experimental and treatment groups, including multiple genotypes, for each in vivo experiment.

\section{Results \\ $\mathrm{H} / \mathrm{H}-\mathrm{N} / \mathrm{N}$ induces ISG expression in WT, but not $T L R 4^{-/-}$, microglia in vitro}

Macrophages trafficking into areas of inflammation experience partial pressures of oxygen $\left(\mathrm{pO}_{2}\right)$ of $4-20 \mathrm{mmHg}$ or $0.5-2.5 \%$. This level of hypoxia is low enough to induce stabilization of HIF- $1 \alpha$ resulting in expression of HIF-1 target genes. Approximately the same $\mathrm{pO}_{2}$ levels $(0.5-2.5 \%)$ have been documented in the ischemic penumbra of rodents (Liu et al., 2006) and other mammals (Liu et al., 2004; Frykholm et al., 2005) undergoing MCAO. We have demonstrated previously that sequential $24 \mathrm{~h}$ intervals of moderate hypoxia (1\% oxygen) combined with hypoglycemia ( $250 \mu$ M glucose) followed by normoxia/normoglycemia $(\mathrm{H} / \mathrm{H}-\mathrm{N} / \mathrm{N})$ induced increased intracellular HIF-1 levels and also increased expression of HIF-1 gene targets vegf and glut 1 in WT primary microglia (Weinstein et al., 2010). We also reported previously that the $\mathrm{H} / \mathrm{H}-\mathrm{N} / \mathrm{N}$ experimental paradigm induced significant differential regulation of individual genes in WT and TLR4 ${ }^{-/-}$microglia (Weinstein et al., 2010).
Table 1. List of ISGs significantly upregulated $>2$-fold in WT primary microglia exposed sequentially to $\mathrm{H} / \mathrm{H}$ for $24 \mathrm{~h}$ and then $\mathrm{N} / \mathrm{N}$ for $24 \mathrm{~h}(\mathrm{H} / \mathrm{H}-\mathrm{N} / \mathrm{N}$ experimental paradigm)

\begin{tabular}{llll}
\hline Symbol & Description of individual ISGs & $\begin{array}{l}\text { Fold } \\
\text { increase }\end{array}$ & p-value \\
\hline Ifit2 & Interferon-induced protein with tetratricopeptide repeats 2 & 4.7 & 0.030 \\
Ifit1 & Interferon-induced protein with tetratricopeptide repeats 1 & 3.5 & 0.026 \\
Cfb & Complement factor B & 3.1 & 0.000021 \\
Irf7 & Interferon regulatory factor 7 & 3.1 & 0.028 \\
Ccl5 & Chemokine (C-C motif) ligand 5 & 3.0 & 0.0076 \\
Oas3 & 2'-5' oligoadenylate synthetase 3 & 2.9 & 0.027 \\
Zbp1 & Z-DNA binding protein 1 & 2.8 & 0.0031 \\
Usp18 & Ubiquitin specific peptidase 18 & 2.8 & 0.016 \\
Rsad2 & Radical S-adenosyl methionine domain containing 2 & 2.8 & 0.036 \\
Timd4 & T-cell immunoglobulin and mucin domain containing 4 & 2.6 & 0.00042 \\
Ly6i & Lymphocyte antigen 6 complex, locus I & 2.6 & 0.000065 \\
Dhx58 & DEXH (Asp-Glu-X-His) box polypeptide 58 & 2.5 & 0.0059 \\
Gbp2 & Guanylate binding protein 2 & 2.5 & 0.0011 \\
Ifi47 & Interferon gamma inducible protein 47 & 2.5 & 0.0079 \\
Mx2 & Myxovirus (influenza virus) resistance 2 & 2.5 & 0.039 \\
Ifi203 & Interferon activated gene 203 & 2.4 & 0.021 \\
Ly6a & Lymphocyte antigen 6 complex, locus A & 2.4 & 0.029 \\
Gbp3 & Guanylate binding protein 3 & 2.3 & 0.0088 \\
Ly6e & Lymphocyte antigen 6 complex, locus E & 2.3 & 0.0024 \\
Cmpk2 & Cytidine monophosphate (UMP-CMP) kinase 2, mitochondrial & 2.2 & 0.049 \\
SIfn8 & Schlafen8 & 2.1 & 0.042 \\
Xaf1 & XIAP associated factor 1 & 2.0 & 0.013 \\
Igtp & Interferon gamma induced GTPase & 2.0 & 0.029 \\
\hline
\end{tabular}

Primary microglia were cultured as described in the Materials and Methods and then exposed to either $\mathrm{H} / \mathrm{H}$ for $24 \mathrm{~h}$ followed by $24 \mathrm{~h}$ of N/N (H/H-N/N) or, as a control, were cultured for $24 \mathrm{~h}$ under N/N conditions followed by a media change and continuance of exposure to $\mathrm{N} / \mathrm{N}$ for an additional $24 \mathrm{~h}(\mathrm{~N} / \mathrm{N}-\mathrm{N} / \mathrm{N})$. Microglia were then collected, RNA was extracted, and a microarray analysis was performed as described in the Materials Methods. Fold upregulation is expressed as $\mathrm{H} / \mathrm{H}-\mathrm{N} / \mathrm{N}$ relative to control (N/N-N/N).

To gain further insight into the ischemia/reperfusion-induced transcriptomal changes in both WT and TLR ${ }^{-1-}$ microglia, we first reanalyzed our microarray data at a higher level of stringency (absolute fold regulation changes $>2.0, p<0.05$ ) and were immediately struck by the preponderance of ISGs present in the $\mathrm{H} / \mathrm{H}-\mathrm{N} / \mathrm{N}$-exposed WT, but not TLR4 ${ }^{-1-}$, microglia (Fig. $2 A$ ). Of the 46 identified genes expressed significantly above the 2 -fold threshold in the $\mathrm{H} / \mathrm{H}-\mathrm{N} / \mathrm{N}$-exposed WT microglia, we identified $23(50 \%)$ that could be readily established as ISGs (Table 1) based on a combination of known promoter sequence and prior reports in the literature. We confirmed ISG status for each gene using the Interferome database (http://www.interferome.org/). Among these 23 genes were prototypical ISGs including IFN regulatory factor 7 (irf7), 2' $-5^{\prime}$ oligoadenylate synthetase 3 (oas3), myxovirus resistance $2(m \times 2)$, ubiquitin specific peptidase 18 (usp18), and chemokine (C-C motif) ligand 5 (ccl5/rantes). In contrast, none of the 23 ISGs was upregulated significantly by exposure to $\mathrm{H} / \mathrm{H}-\mathrm{N} / \mathrm{N}$ in the TLR $4^{-1-}$ microglia (Fig. $2 B$ ) and no other $\mathrm{H} / \mathrm{H}-\mathrm{N} / \mathrm{N}$-induced ISGs were identified in the TLR $4^{-1-}$ microglia.

\section{$\mathrm{H} / \mathrm{H}-\mathrm{N} / \mathrm{N}$ induces activation of IFN regulatory TFs in WT, but not $T L R 4^{-1-}$, microglia}

We next performed a bioinformatic TFBS analysis on the regulatory regions of the $\mathrm{H} / \mathrm{H}-\mathrm{N} / \mathrm{N}$-regulated genes in the WT primary microglia. Of a total of 283 TFBSs analyzed, 48 were represented at levels significantly above the transcriptional background. The four TFs with the highest statistical association were ISG factor 3 (ISGF3), IRF2, IRF1, and IRF7 (Table 2), all known downstream targets of type 1 IFN signaling. Therefore, $\mathrm{H} / \mathrm{H}-\mathrm{N} / \mathrm{N}$ induced a robust, TLR4-dependent, genomic response in primary microglia that implicated a specific subset of IFN signaling pathways. In 


\begin{tabular}{lcc}
$\begin{array}{l}\text { Table 2. TFBS/promoter analysis of the regulatory regions of significantly } \\
\text { upregulated genes in WT primary microglia exposed to } \mathbf{H} / \mathbf{H}-\mathrm{N} / \mathrm{N}\end{array}$ \\
\hline TF & Rank & \\
\hline ISGF3 & 1 & Z-score \\
IRF-2 & 2 & 7.44 \\
IRF-1 & 3 & 5.99 \\
IRF-7 & 4 & 5.80 \\
AP-1 & 5 & 4.70 \\
GATA-1 & 6 & 3.66 \\
RFX1 & 7 & 3.30 \\
NFkB & 8 & 3.29 \\
Elk-1 & 9 & 3.28 \\
Bach1 & 10 & 3.00 \\
NF1 & 11 & 2.79 \\
Freac-3 & 12 & 2.71 \\
\hline
\end{tabular}

Results of bioinformatic TFBS/promoter analysis on the regulatory regions of significantly upregulated ( $>2.0$ fold $p<0.05)$ genes in WT primary microglia exposed sequentially to $\mathrm{H} / \mathrm{H}$ for $24 \mathrm{~h}$ and then N/N for $24 \mathrm{~h}(\mathrm{H} / \mathrm{H}-\mathrm{N} / \mathrm{N}$ experimental paradigm). All Z-scores indicated had statistical significance of $p<0.01$. IRFs are indicated in bold.

addition to the four immunomodulatory IRFs identified, other $\mathrm{H} / \mathrm{H}-\mathrm{N} / \mathrm{N}$-activated TFs in the WT microglia included classical proinflammatory factors such as activator protein-1 (AP-1), $\mathrm{NF}-\kappa \mathrm{B}$, the erythroid cell TF GATA1, and the cell growth suppressing TF nuclear factor 1 (NF1).

\section{$\mathrm{H} / \mathrm{H}-\mathrm{N} / \mathrm{N}$-induced ISG response is dependent on intact IFNAR1}

To confirm the $\mathrm{H} / \mathrm{H}-\mathrm{N} / \mathrm{N}$-induced ISG response in microglia, we performed qRT-PCR analyses on separate primary microglial cultures that had been exposed to $\mathrm{H} / \mathrm{H}-\mathrm{N} / \mathrm{N}$ with a panel of primer/probe sets corresponding to six ISGs identified in our microarray: Ifit1, Ifit2, Irf7, Oas3, Usp 18, and Mx2. We found that exposure to ischemia/reperfusion-like $(\mathrm{H} / \mathrm{H}-\mathrm{N} / \mathrm{N})$ conditions increased the expression of all six ISGs significantly (Fig. 2C). The magnitude of the ISG upregulation varied from just under 2-fold to $>4$-fold. These changes were consistent with those seen in our microarray data (Table 1). To determine the extent to which the $\mathrm{H} / \mathrm{H}-\mathrm{N} / \mathrm{N}$-induced ISG response in microglia was dependent on type 1 IFN receptor IFNAR1, we exposed primary microglia derived from IFNAR $1^{-1-}$ mice to $\mathrm{H} / \mathrm{H}-\mathrm{N} / \mathrm{N}$ in parallel with WT microglia. In contrast to the WT microglia, in IFNAR $1^{-/-}$microglia, $\mathrm{H} / \mathrm{H}-$ $\mathrm{N} / \mathrm{N}$ failed to induce significantly increased expression in any of the ISGs examined on our aforementioned qRT-PCR panel (Fig. 2D). $\mathrm{H} / \mathrm{H}-\mathrm{N} / \mathrm{N}$ did not induce increased expression of two additional ISGs that we tested ( $\operatorname{tnfsf10}$ and $c x c l 10$ ) in IFNAR $1^{-1-}$ microglia (Fig. 2D). Therefore, our data demonstrate that the ISG response to $\mathrm{H} / \mathrm{H}-\mathrm{N} / \mathrm{N}$ in microglia is dependent on intact IFNAR1.

\section{$\mathrm{H} / \mathrm{H}-\mathrm{N} / \mathrm{N}$ induces time-dependent changes in phosphorylation of STAT1}

IFN- $\beta$ and all of the IFN- $\alpha$ subtypes bind to, and signal through, IFNAR, a heterodimeric transmembrane receptor composed of the subunits IFNAR1 and IFNAR2 (Ivashkiv and Donlin, 2014; $\mathrm{McNab}$ et al., 2015). Ligation of IFNAR activates the receptorassociated protein tyrosine kinases Janus kinase 1 (JAK1) and tyrosine kinase 2 (TYK2). In the canonical pathway of IFN- $\alpha / \beta$ mediated signaling, activated JAK1 and TYK2 phosphorylate STAT1 and STAT2 molecules that are present in the cytosol, leading to the dimerization, nuclear translocation, and binding of these molecules to IRF9 to form the ISGF3 complex. This complex then binds to IFN-stimulated response cis-elements (ISREs) in ISG promoters, leading to the transcription of ISGs (Ivashkiv and Donlin, 2014; McNab et al., 2015). We hypothesized that, in primary WT microglia, ischemia/reperfusion would lead to activation of the IFN signaling pathway via phosphorylation of STAT1. We sought to test this hypothesis by culturing WT microglia and exposing them to our $\mathrm{H} / \mathrm{H}-\mathrm{N} / \mathrm{N}$ experimental paradigm (Fig. $1 \mathrm{~A}$ ) and then assessing the level of STAT1 phosphorylation at multiple time points using flow cytometry (Fig. 3). Our results indicate dynamic and complex temporal changes in the level of STAT1 phosphorylation in the $\mathrm{H} / \mathrm{H}-\mathrm{N} / \mathrm{N}$-exposed microglia with variable levels early after exposure to hypoxia/hypoglycemia, marked downregulation later in the hypoxia/hypoglycemia time course, and then partial recovery toward baseline levels after reintroduction of normoxic/normoglycemic conditions (Fig. $3 A, C$ ). Despite this dynamic, and at times robust, induction of STAT1 phosphorylation at early time points of hypoxia/hypoglycemia exposure, changes observed during the time course of our study were not statistically significant $(F$ value $=1.179, p=0.3295$, ANOVA), which does not necessarily rule out biological consequences of variations in pSTAT1 levels. In addition, we demonstrated that exposure to IFN- $\beta$ induced robust and rapid phosphorylation of STAT1 in WT microglia $(t=10.24, p<$ 0.0001 , unpaired $t$ test; Fig. $3 B$ ). Exposure to TLR4 agonist LPS for $3 \mathrm{~h}$ induced variable levels of phosphorylation of STAT1 in WT, but not IFNAR1 $1^{-1-}$, microglia (data not shown).

We noted that, in WT microglia, there was considerable variability in the extent of STAT1 phosphorylation at the canonical Tyr-701 site induced by either IFN- $\beta$ (Fig. $3 B$ ) or hypoxia/hypoglycemia (Fig. 3C). We considered the possibility that this variability might be due in part to the physiological state of the microglia before stimulation. In particular, a recent study (Parajuli et al., 2012) demonstrated that pretreatment of microglia with high doses $(20$ $\mathrm{ng} / \mathrm{ml}$ ) of GM-CSF for $48 \mathrm{~h}$ increased expression of TLR 4 and CD14, both of which are closely linked to type 1 IFN signaling in microglia (Zanoni et al., 2011; Janova et al., 2016). In our microglial culture paradigm, microglia are exposed to low concentrations of GM-CSF $(2 \mathrm{ng} / \mathrm{ml}$ ) during the mixed glial culture phase (Witting and Möller, 2011). At this concentration, GM-CSF is reported to have minimal or no effect on microglial response to a variety of agonists (Esen and Kielian, 2007). Nevertheless, we wanted to further explore the potential effects of GM-CSF on this specific parameter, so we performed pilot studies examining the effects of pretreatment for $48 \mathrm{~h}$ with varying concentrations of GM-CSF $(0,0.2,2$, and $20 \mathrm{ng} / \mathrm{ml})$ on hypoxia/hypoglycemiainduced phosphorylation of STAT1. None of the concentrations of GM-CSF tested resulted in a change in the ability of hypoxia/ hypoglycemia to induce phosphorylation of STAT1, although the highest concentration $(20 \mathrm{ng} / \mathrm{ml})$ boosted IFN- $\beta$-induced STAT1 phosphorylation significantly (data not shown). Other potential physiologic causes of this variability are more difficult to assess experimentally but might include differences in the overall cell cycle state (Stephanou and Latchman, 2005; Swiatek-Machado and Kaminska, 2013) and/or extent of intracellular glycogen storage (Fuchs et al., 1998; Hu et al., 2007) of the microglia population at time of exposure to hypoxia/hypoglycemia. Notably, in TLR $4^{-/-}$microglia, there was consistently no pSTAT1 response to hypoxia/hypoglycemia (data not shown).

\section{$\mathrm{H} / \mathrm{H}$ does not induce detectable release of type 1 IFNs from microglia}

Microglia can produce and release type 1 IFNs after stimulation with various TLR ligands (Town et al., 2006; Kapil et al., 2012; Janova et al., 2016). Given the ISG response that we observed in microglia after exposure to $\mathrm{H} / \mathrm{H}-\mathrm{N} / \mathrm{N}$, we hypothesized that this ISG response could be induced by an autocrine/paracrine mecha- 
A

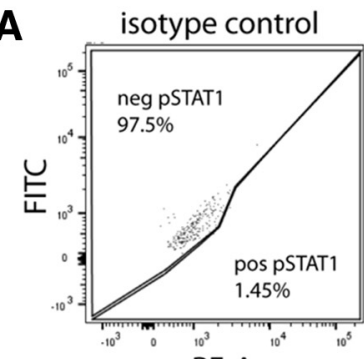

PE-A

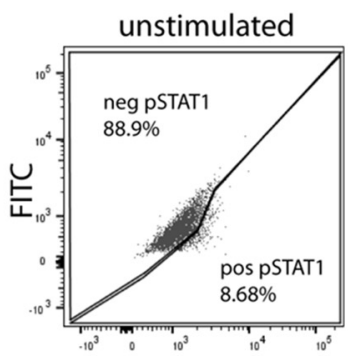

PE-A

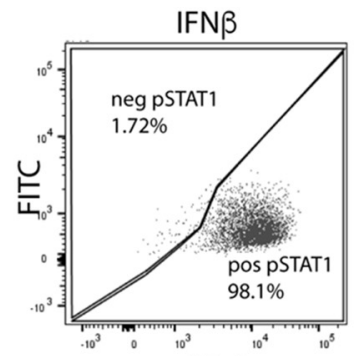

PE-A

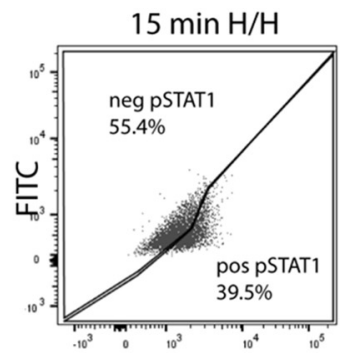

PE-A
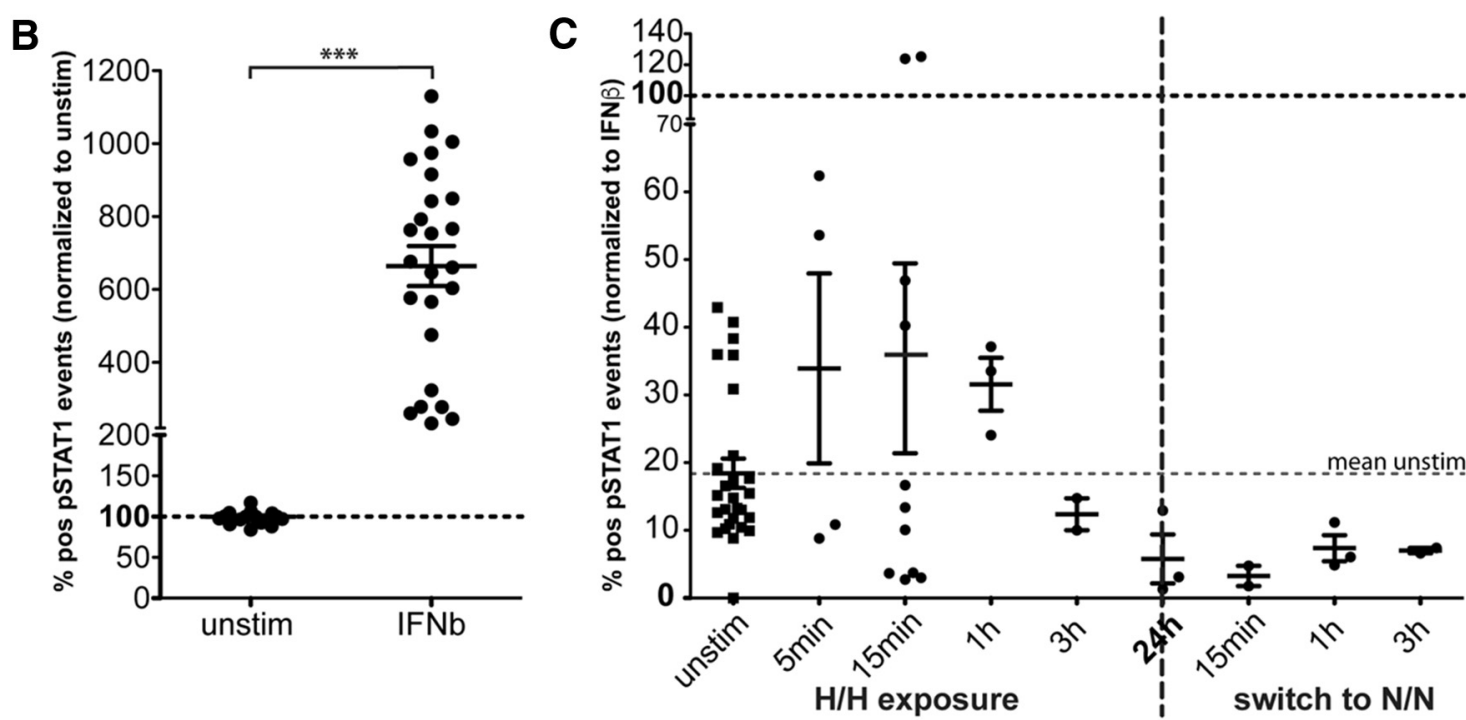

Figure 3. Temporal dynamics of STAT1 phosphorylation during both exposure to $\mathrm{H} / \mathrm{H}$ and after restoration of N/N conditions. A, Flow cytometry dot plots show percentage of anti-pSTAT1 antibody-positive or negative staining cellular events after exposure for $15 \mathrm{~min}$ to $1000 \mathrm{U} / \mathrm{ml}$ recombinant mouse IFN- $\beta$ (positive control), $\mathrm{N} / \mathrm{N}$ (unstimulated) or $\mathrm{H} / \mathrm{H}$ conditions. Background signal obtained with isotype control antibody is shown as a negative control. $\boldsymbol{B}$, Vertical scatter plot quantifying levels of pSTAT1-positive events in microglia after exposure to 15 min IFN- $\beta$. All values in $\boldsymbol{B}$ are normalized to the mean of median values for pSTAT1-positive events for unstimulated cells $\left(t=10.24,{ }^{* * *} p<0.0001\right.$, unpaired $t$ test). $\boldsymbol{C}$, Vertical scatter plot quantifying levels of pSTAT1-positive events in microglia throughout the $\mathrm{H} / \mathrm{H}-\mathrm{N} / \mathrm{N}$ experimental paradigm time course. Mean \pm SEM values are shown. All values in C are normalized to those from IFN- $\beta$-treated cells to adjust for differences in microglial reactivity present in different cell preparations.

nism featuring release of type 1 IFNs from microglia under ischemia/ reperfusion-like conditions. To test this hypothesis, we exposed WT microglia for $24 \mathrm{~h}$ to either hypoxia/hypoglycemia (Fig. 1A, time point $a$ ), the TLR3 agonist poly(I:C), or the TLR4 agonist LPS, and then assayed conditioned medium for IFN- $\alpha$ and IFN- $\beta$ using highsensitivity ELISAs as described previously (Janova et al., 2016). We found that exposure to poly(I:C) induced robust secretion of both IFN- $\alpha$ and IFN- $\beta$, whereas LPS treatment induced moderate release of IFN- $\beta$, but not IFN- $\alpha$, from microglia. Exposure to hypoxic/hypoglycemic conditions did not induce any detectable microglial release of IFN- $\alpha$ or IFN- $\beta$ (Fig. $4 A$ ).

\section{H/H eliminates microglial surface expression of IFNAR1}

TLR4 activation via hypoxia/hypoglycemia is followed by one or more of several possibilities including: release of low $(<10 \mathrm{pM})$ concentrations (undetectable by ELISA as we report in Fig. $4 A$ ) of type 1 IFNs that in turn activate IFNAR1 via classical extracellular high-affinity ligand-receptor docking (Ivashkiv and Donlin, 2014) or induction of ligand-independent IFNAR1 activation and endocytosis (Liu et al., 2008). Our data presented in Figure 2, $C$ and $D$, showed that the microglial ISG response to $\mathrm{H} / \mathrm{H}-\mathrm{N} / \mathrm{N}$ was dependent on intact type 1 IFN receptor IFNAR1. Prior studies have established that stimulation with type 1 IFNs result in rapid ubiquitination, endocytosis, and proteolytic degradation of IFNAR1 (Kumar et al., 2003). Here, we sought to characterize the effects of ischemia-like conditions on the expression of IFNAR1 in microglia with our hypothesis being that exposure to hypoxia/ hypoglycemia would result in a decrease in surface expression of IFNAR1 because activated IFNAR would be endocytosed and degraded. We quantified the effect of hypoxia/hypoglycemia on cell surface expression of IFNAR1 in microglia using flow cytometry and found that hypoxia/hypoglycemia induced near complete loss $(98 \%$ reduction) of specific binding for anti-IFNAR1 antibody (Fig. $4 B, C)$. We considered the possibility that this dramatic reduction in IFNAR1 surface expression might be due to generalized metabolic shutdown in the setting of hypoxia/hypoglycemia; however, none of the other microglial surface antigens measured, including CD64, CD45, TLR4, and F4/80, exhibited such a robust reduction in surface expression and one of them (F4/80) increased substantially (Fig. 4C). Therefore, these findings are not likely explained solely by loss of energy substrate under hypoxic/hypoglycemic conditions. We also confirmed the specificity of our assay by demonstrating that stimulation with IFN- $\beta(1000 \mathrm{U} / \mathrm{ml} \times 24 \mathrm{~h})$ induced near complete loss (99\% reduction) of specific binding for anti-IFNAR1 antibody (Fig. $4 D, E$ ), but either increased or induced no change in the other microglial surface antigens (Fig. 4E).

\section{IFN- $\boldsymbol{\beta}$ induces robust ISG expression in both $\mathrm{WT}$ and TLR4 ${ }^{-/-}$microglia}

We hypothesize that the TLR4 dependence of the ISG response is the result of microglial release of DAMPs that activate TLR4 on the microglial cell surface in an autocrine/paracrine manner 


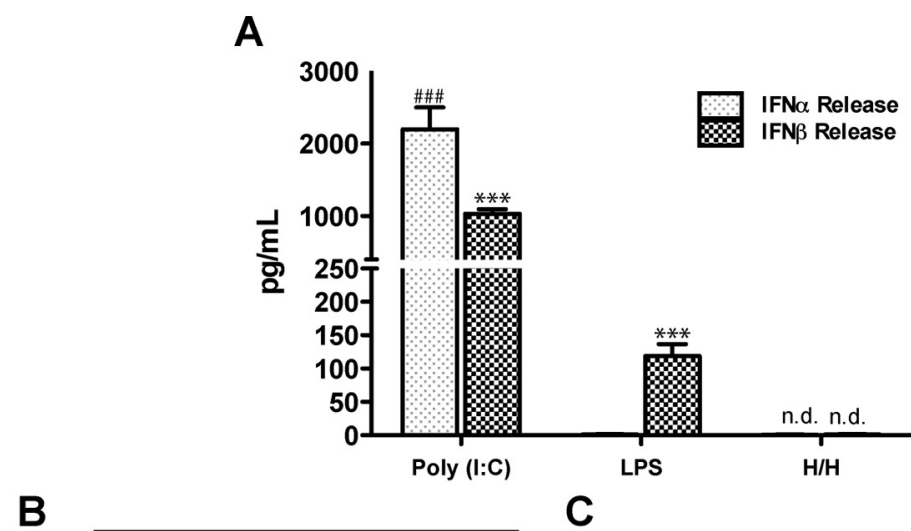

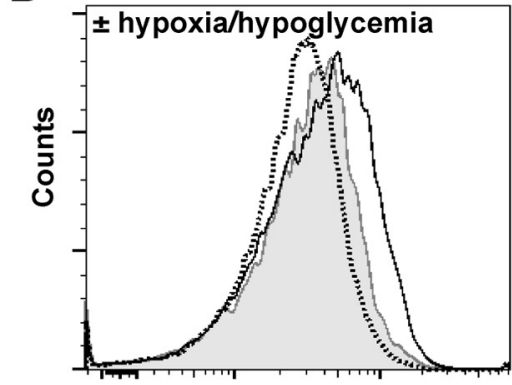

PE-anti-IFNAR1

D

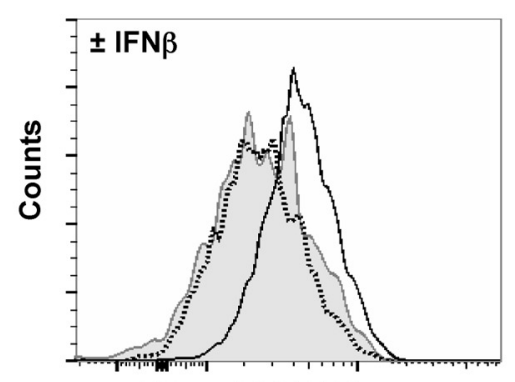

PE-anti-IFNAR1

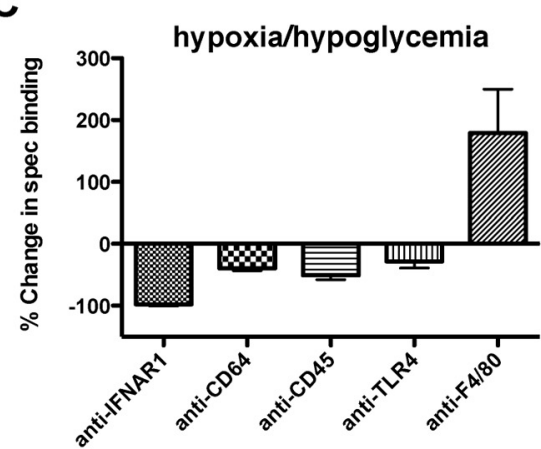

E

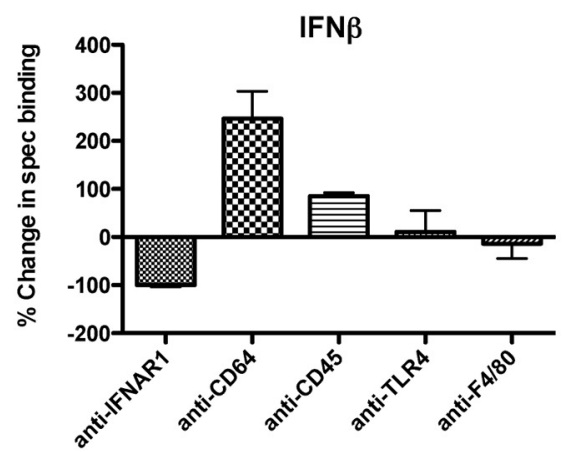

Figure 4. Exposure to TLR agonists, but not $\mathrm{H} / \mathrm{H}$, induces release of type 1 IFNs from microglia. Both $\mathrm{H} / \mathrm{H}$ and IFN- $\beta$ eliminate cell surface expression of IFNAR1. A, Type I IFNs are released in response to TLR3 and TLR4 agonists, but not in response to $\mathrm{H} / \mathrm{H}$. Shown is a bar graph quantifying levels of type 1 IFNs released from WT primary microglia that were cultured under conditions of $\mathrm{H} / \mathrm{H}$ for $24 \mathrm{~h}$ or separately stimulated with either the TLR3 agonist poly $(\mathrm{l}: \mathrm{C})(10 \mu \mathrm{g} / \mathrm{ml})$ or the TLR4 agonist LPS (100 EU/ml) for $24 \mathrm{~h}$ under N/N conditions. Conditioned medium was collected for high-sensitivity ELISAs for both IFN- $\alpha$ and IFN- $\beta$ as described in the Materials and Methods. Mean \pm SEM values are shown. \#\#\# $=0.0020$ compared with unstimulated control for IFN- $\alpha$. ${ }^{* * *} p<$ 0.001 compared with unstimulated control for IFN- $\beta$; poly (I:C), $t=2718, p<0.0001$; LPS, $t=10.04, p<0.0001$, unpaired $t$ tests. $N=9$ conditioned medium samples from 3 separate experiments for both IFN- $\alpha$ and IFN- $\beta$ ELISAs for each stimulus and time point. $\boldsymbol{B}, \boldsymbol{D}$, Flow cytometry histograms showing fluorescent intensity signal for differently treated microglial cell populations. Unstimulated cells were stained with phycoerythrin (PE)-conjugated isotype control antibody (gray shading) or anti-IFNAR1 antibody (dark lines). Microglia exposed for $24 \mathrm{~h}$ to $\mathrm{H} / \mathrm{H}$ (ischemia-like conditions; $\boldsymbol{B}$ ) or $1000 \mathrm{U} / \mathrm{ml}$ of IFN- $\beta$ (D) were also stained with anti-IFNAR1 antibody (dashed lines). $\boldsymbol{C}, \boldsymbol{E}$, Bar graphs quantifying percentage change in specific binding of fluorochrome-conjugated antibodies against a panel of surface receptors including IFNAR1, CD64, CD45, TLR4, and F4/80 in primary microglia exposed for $24 \mathrm{~h}$ to $\mathrm{H} / \mathrm{H}$ (C) or $1000 \mathrm{U} / \mathrm{ml}$ of IFN- $\beta(\boldsymbol{E}) . N=3$ experiments with 9 samples per treatment group total. In $\boldsymbol{C}$ and $\boldsymbol{E}$, mean \pm SEM of median values for anti-IFNAR1 antibody specific signal, normalized to unstimulated, are shown.

(Lehnardt et al., 2008; Qiu et al., 2008; Shichita et al., 2012b). Due to limitations with our in vitro hypoxia/hypoglycemia model discussed below, we used other less complex in vitro paradigms to assess directly the effects of the relevant type 1 IFN and TLR agonists on microglial ISG expression for controlled dissection of intracellular mechanisms that could be involved in the microglial response to ischemia/reperfusion-like conditions. To gain further insight into the ability of WT microglia to respond to type 1 IFNs and to ensure that TLR4 ${ }^{-1-}$ microglia, which, unlike WT microglia, did not upregulate ISGs in response to H/H-N/N (Fig. $2 A, B)$, were still intrinsically capable of activating a type 1 IFN transcription program, we stimulated both $\mathrm{WT}$ and TLR4 ${ }^{-1-}$ microglia with recombinant mouse IFN- $\beta(1000 \mathrm{U} / \mathrm{ml})$ for $6 \mathrm{~h}$ and quantified changes in steady-state levels of mRNA for numerous ISGs using a type 1 IFN gene targeted qRT-PCR array. We found that IFN- $\beta$ induced broad and robust ISG expression in both WT and TLR4 $4^{-1-}$ microglia (Fig. 5A-D). Prototypical ISGs highly induced in both WT and TLR4 ${ }^{-1-}$ microglia included isg20, oas2, irf7, $g b p 1$, myxovirus resistance 1 ( $m \times 1)$, ifit1, and $\operatorname{cxcl10}$. Many of the IFN- $\beta$-induced genes significantly upregulated in both WT and TLR4 ${ }^{-1-}$ microglia included ones we had seen induced only in WT microglia by $\mathrm{H} / \mathrm{H}-\mathrm{N} / \mathrm{N}$, including 
A

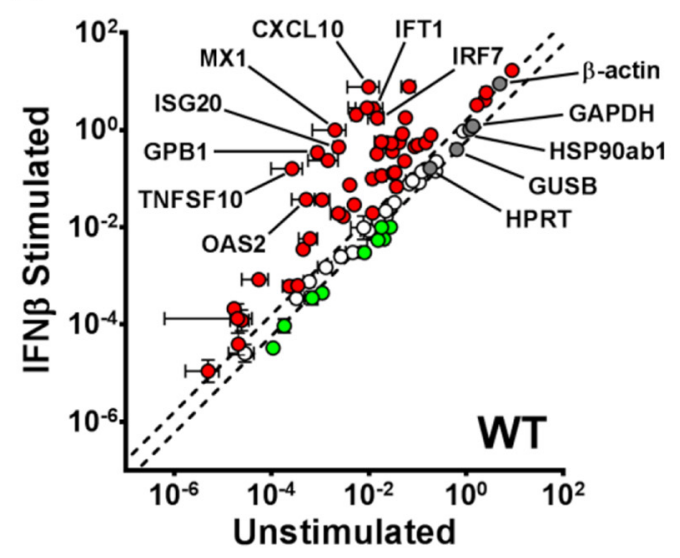

C

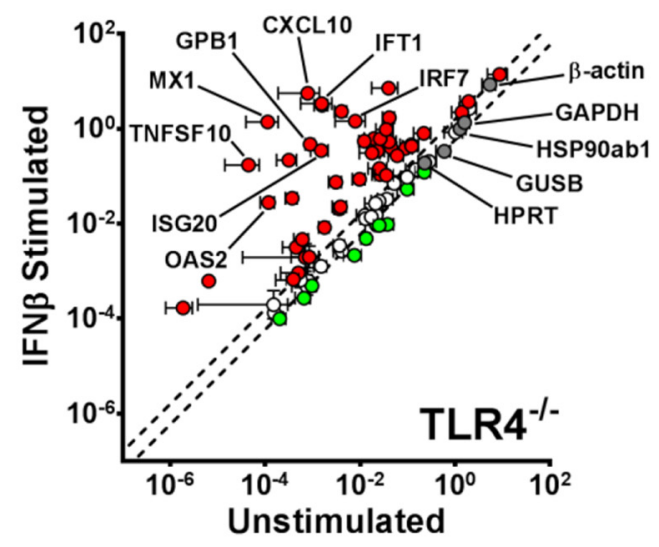

B

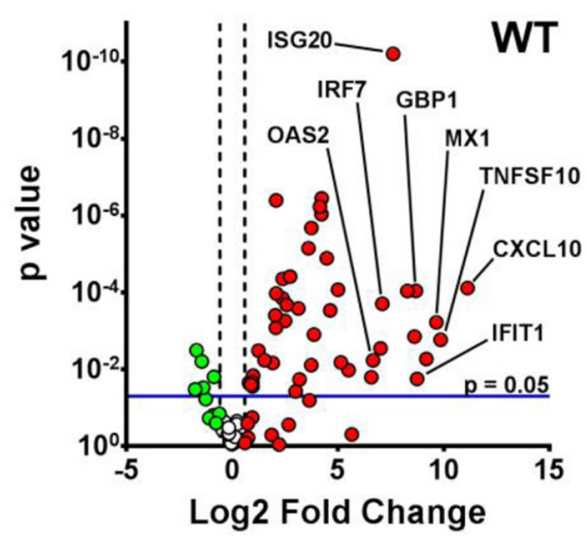

D

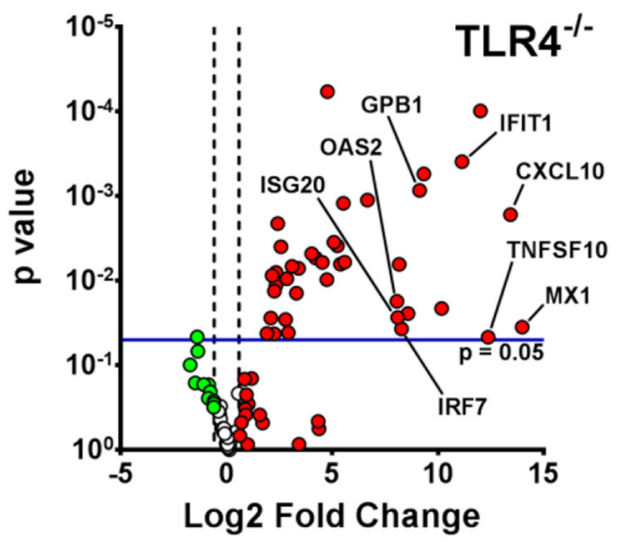

$\mathbf{E}$

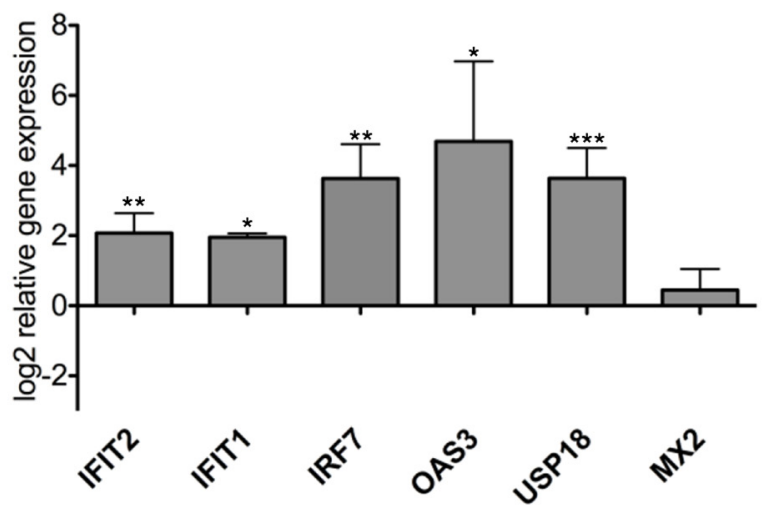

Figure 5. IFN- $\beta$ induces a broad and robust ISG expression response in both WT and TLR4 $4^{-1-}$ microglia. Relative gene expression level scatter $(\boldsymbol{A}, \boldsymbol{C})$ and volcano $(\boldsymbol{B}, \boldsymbol{D})$ plots showing results of type 1 IFN-targeted PCR array assays on both WT $(\boldsymbol{A}, \boldsymbol{B})$ and TLR4 ${ }^{-1-}(\boldsymbol{C}, \boldsymbol{D})$ microglia that had been exposed to $1000 \mathrm{U} / \mathrm{ml}$ of IFN- $\beta$ for 6 h. Individual upregulated (>1.5-fold) ISGs are shown as red filled circles. Downregulated ( $<0.75$ fold) ISGs are shown as green filled circles. ISGs not significantly regulated are shown as open circles. Housekeeping genes are shown as gray-filled circles. Multiple ISGs, but not housekeeping genes, are significantly and robustly upregulated by IFN- $\beta$ in both WT and $T L R 4^{-1}$ - microglia. $N=3$ for each experimental group and genotype, respectively. E, qRT-PCR quantification of microglial expression of six selected ISGS $24 \mathrm{~h}$ after intracerebroventricular injection of $2000 \mathrm{U}$ of recombinant mouse IFN- $\beta$ into WT adult mice. Expression levels were normalized to a panel of housekeeping genes and are presented as relative to expression in microglia isolated from cortical tissue of saline (vehicle) intracerebroventricularly injected mice. Mean \pm SEM values are shown. $N=3$ experiments for each treatment group. ${ }^{*} p<0.05,{ }^{* *} p<0.01,{ }^{* * *} p<0.001$. Individual $p$-values (unpaired $t$ test) are as follows: ifit2, $p=0.0029 ;$ ifit $1, p=0.0468$; irf7, $p=0.0032 ;$ oas $3, p=0.0122 ;$ usp $18, p=0.0003 ;$ and $m \times 2, p=0.3864$.

irf7, gbp2, and ifit1 (Fig. 2B). Other IFN- $\beta$-induced ISGs were ones that were not induced by $\mathrm{H} / \mathrm{H}-\mathrm{N} / \mathrm{N}$ in WT microglia ( such as cxcl10, ifnb1, and isg20), most likely reflecting the greater potency of stimulation by a relatively high concentration of IFN- $\beta$. To demonstrate that the microglial response to IFN- $\beta$ could also be seen in vivo, we performed qRT-PCR analyses on ex vivo sorted cortical microglia isolated from cortex of WT mice that had been exposed $24 \mathrm{~h}$ earlier to intracerebroventricular injection of IFN- $\beta$, as described in the Materials and Methods, using our panel of primer/probe sets corresponding to six well defined ISGs. We found that exposure to ICV injection of IFN- $\beta$ increased expression of five of six of these ISGs significantly and robustly in the sorted microglia (Fig. 5E). 

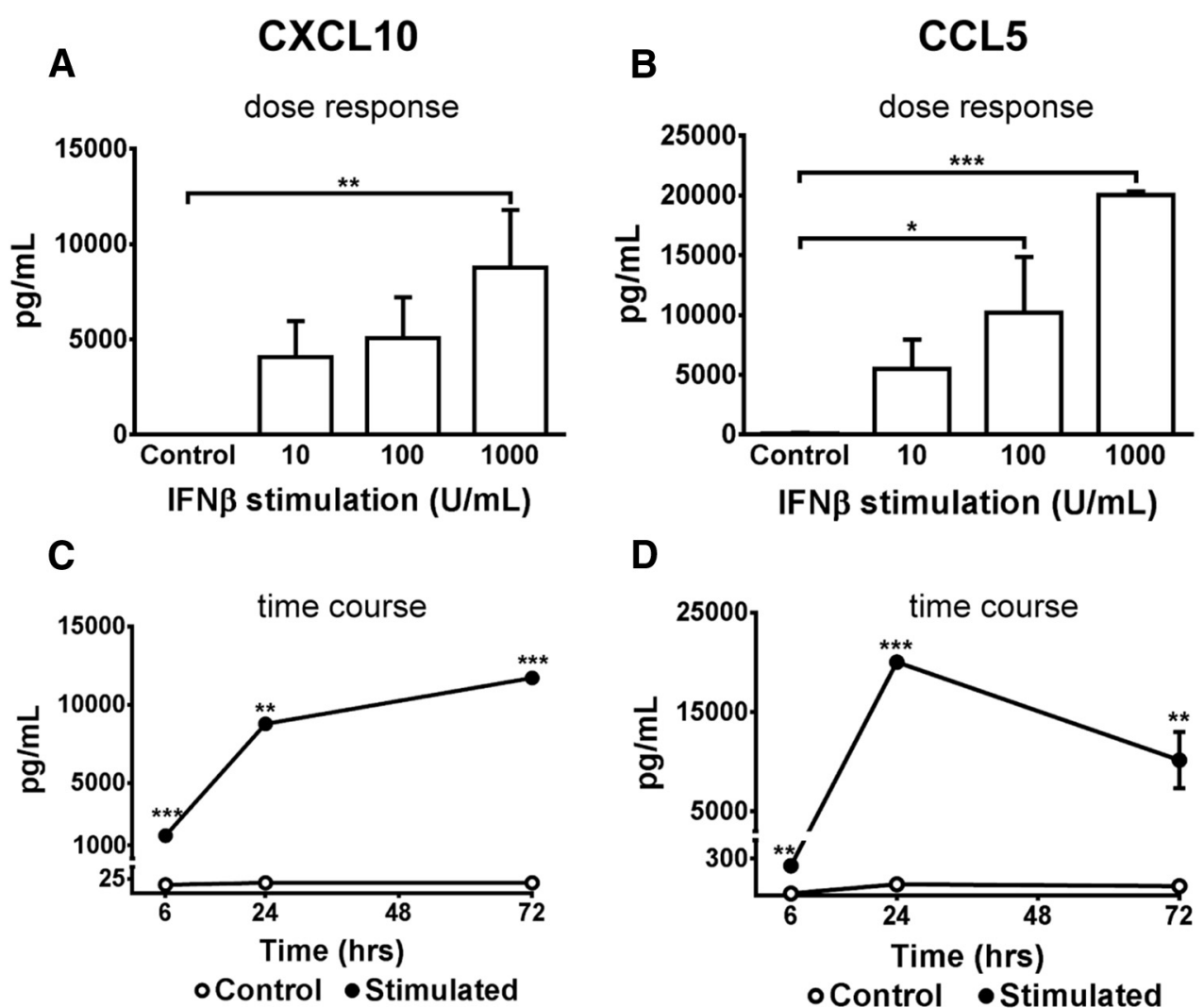

D

E

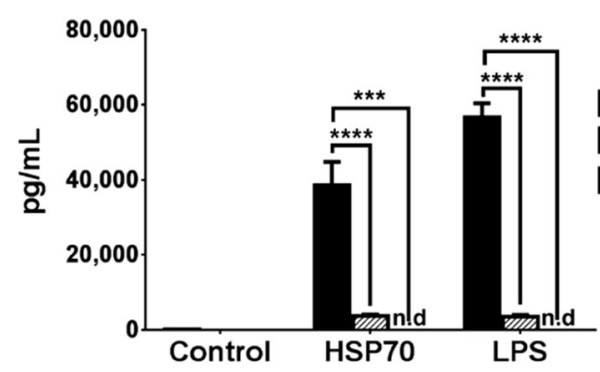

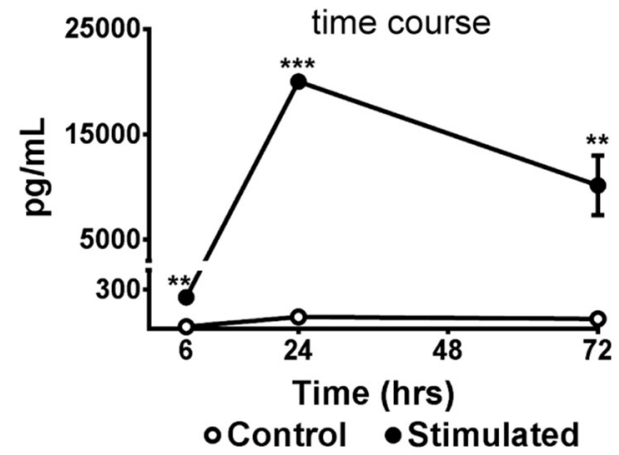

$\mathbf{F}$

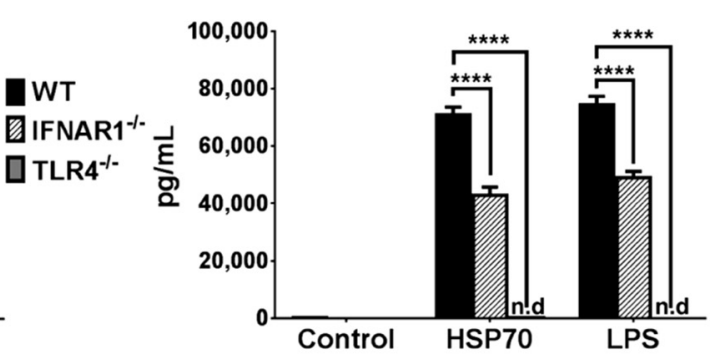

Figure 6. Both IFN- $\beta$ and TLR4 agonist stimulation induce robust production and release of $C X C L 10$ and CCL5 5 in primary microglia. Bar graphs show dose-dependent release of CXCL10 (** $p<$ 0.01; Dunnett's multiple-comparison test; one-way ANOVA post test; $A$ ) and $C C L 5\left({ }^{*} p<0.05\right.$ and ${ }^{* * *} p<0.001$; Dunnett's multiple-comparisons test; one-way ANOVA post test; $\left.\boldsymbol{B}\right)$ in picograms per milliliter as determined by ELISA in conditioned medium from WT microglia after $24 \mathrm{~h}$ exposure to the indicated concentrations of recombinant mouse IFN- $\beta$. Line graphs show time course for release of CXCL10 (6h, $p<0.0001 ; 24 \mathrm{~h}, p=0.0015,72 \mathrm{~h}, p<0.0001$; unpaired t tests control vs treatment; $\mathrm{C}$ ) and CCL5 (6h, $p=0.0030 ; 24 \mathrm{~h}, p<0.001,72 \mathrm{~h}, p=0.0021$; unpaired $t$ tests control vs treatment; $\boldsymbol{D}$ ) in conditioned medium from WT microglia after exposure to $1000 \mathrm{U} / \mathrm{ml}$ of IFN- $\beta$ for the indicated time intervals. $N=9$ conditioned medium samples from 3 separate experiments for each IFN- $\beta$ concentration and time point. ${ }^{*} p<0.05,{ }^{* *} p<0.01,{ }^{* * *} p<0.001$ for stimulated samples relative to appropriate controls. $E, F$, TLR4-agonist-induced release of $C X C L 10$ and $C C L 5$ secretion in microglia is dependent on both TLR4 and IFNAR1. Bar graphs show release of CXCL10 (E) and CCL5 $(\boldsymbol{F})$ into culture medium from WT, TLR4 ${ }^{-1-}$, or IFNAR1 ${ }^{-1-}$ microglia after $24 \mathrm{~h}$ exposure to TLR4 agonists. HSP70 at $10 \mu \mathrm{g} / \mathrm{ml}$ or LPS at $100 \mathrm{EU} / \mathrm{ml}$ were administered and levels of secreted chemokines were measured by ELISA as described in the Materials and Methods. $N=$ $6-12$ conditioned medium samples from 3 separate experiments for each agonist and microglial genotype. ${ }^{* * *} p<0.001,{ }^{* * * *} p<0.0001$ for stimulated samples in WT microglia relative to

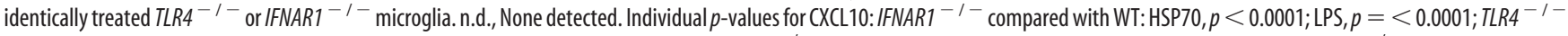
compared with WT: HSP 70, $p=0.0015 ;$ LPS, $p<0.0001$. Individual $p$-values for CCL5: IFNAR1 ${ }^{-1-}$ compared with WT: HSP70, $p<0.0001 ;$ LPS, $p=<0.0001 ;$ TLR4 $^{-1-}$ compared with WT: HSP70, $p<0.0001 ;$ LPS, $p<0.0001$.

TLR4-mediated microglial production of ISG chemokines CXCL10 and CCL5 is dependent on IFNAR1

We next determined whether stimulation of microglia with IFN- $\beta$ directly could induce ISG expression at the protein level. We chose to focus on two well characterized ISG chemokines, CXCL10 (Ohmori and Hamilton, 1993) and CCL5 (Lin et al., 1999), and measured their IFN- $\beta$-induced release into conditioned medium. After $24 \mathrm{~h}$ of exposure, IFN- $\beta$ induced a dose-dependent release for both CXCL10 and CCL5 starting at a concentration of
$10 \mathrm{U} / \mathrm{ml}($ CXCL10: $F$ value $=5.614, p=0.0080 ;$ CCL5: $F$ value $=$ $10.39, p=0.0007$; one-way ANOVAs; Fig. $6 A, B$ ). The time course of IFN- $\beta$-induced chemokine release showed that CXCL10 levels continued to increase at $72 \mathrm{~h}$ (Fig. $6 \mathrm{C}$ ), whereas the highest CCL5 levels were measured at $24 \mathrm{~h}$ (Fig. $6 \mathrm{D}$ ).

Observing that TLR4 is required for $\mathrm{H} / \mathrm{H}-\mathrm{N} / \mathrm{N}$-induced ISG expression and that hypoxia/hypoglycemia eliminates surface expression of IFNAR1 in microglia, we sought to determine whether TLR4 agonists could induce ISG chemokine production and secre- 
Table 3. ISGs are significantly upregulated in ex vivo-sorted microglia after ischemia/reperfusion

\begin{tabular}{|c|c|c|c|c|}
\hline Symbol & Description of individual ISGs & Fold increase & $p$-value & Adjusted $p$-value \\
\hline Cxcl10 & Chemokine (C-X-C motif) ligand 10 & 19.7 & 0.00000023 & 0.00019 \\
\hline Ifi27I $2 a$ & Interferon, alpha-inducible protein 27 like $2 \mathrm{~A}$ & 10.1 & 0.000017 & 0.00025 \\
\hline Ifit2 & Interferon-induced protein with tetratricopeptide repeats 2 & 7.3 & 0.0000099 & 0.00025 \\
\hline $\mathrm{Cd} 15$ & Chemokine (C-C motif) ligand 5 & 6.1 & 0.00026 & 0.015 \\
\hline Ifi44 & Interferon-induced protein 44 & 5.7 & 0.000020 & 0.0028 \\
\hline Oas/2 & 2'-5' oligoadenylate synthetase-like 2 & 5.7 & 0.00010 & 0.0082 \\
\hline Ifit1 & Interferon-induced protein with tetratricopeptide repeats 1 & 5.4 & 0.00043 & 0.021 \\
\hline Ifi204 & Interferon activated gene 204 & 5.0 & 0.000041 & 0.0044 \\
\hline Ifi205 & Interferon activated gene 205 & 4.6 & 0.0014 & 0.042 \\
\hline Ifit3 & Interferon-induced protein with tetratricopeptide repeats 3 & 4.5 & 0.000099 & 0.0081 \\
\hline Ly6a & Lymphocyte antigen 6 complex, locus A & 4.5 & 0.00017 & 0.011 \\
\hline Usp18 & Ubiquitin specific peptidase 18 & 4.0 & 0.00087 & 0.032 \\
\hline Irf7 & Interferon regulatory factor 7 & 3.8 & 0.00011 & 0.0087 \\
\hline Csf1 & Colony stimulating factor 1 & 3.7 & 0.0000029 & 0.00008 \\
\hline Ifitm3 & Interferon induced transmembrane protein 3 & 3.6 & 0.000016 & 0.0024 \\
\hline Oas1g & $2^{\prime}-5^{\prime}$ oligoadenylate synthetase $1 \mathrm{G}$ & 3.5 & 0.00030 & 0.016 \\
\hline lsg15 & ISG15 ubiquitin-like modifier & 3.5 & 0.00026 & 0.015 \\
\hline Ifitm2 & Interferon induced transmembrane protein 2 & 3.2 & 0.0000021 & 0.00064 \\
\hline Gbp2 & Guanylate binding protein 2 & 3.2 & 0.0013 & 0.041 \\
\hline Csprs & Component of Sp100-rs & 3.0 & 0.00046 & 0.022 \\
\hline$M \times 1$ & Myxovirus (influenza virus) resistance 1 & 2.9 & 0.0016 & 0.047 \\
\hline Oas2 & $2^{\prime}-5^{\prime}$ oligoadenylate synthetase 2 & 2.9 & 0.00034 & 0.018 \\
\hline $\mathrm{CCl} 2$ & Chemokine (C-C motif) ligand 2 & 2.9 & 0.00013 & 0.0094 \\
\hline Oas1a & $2^{\prime}-5^{\prime}$ oligoadenylate synthetase $1 \mathrm{~A}$ & 2.8 & 0.0033 & 0.069 (NS) \\
\hline $\mathrm{Cd} 12$ & Chemokine (C-C motif) ligand 12 & 2.8 & 0.000026 & 0.0033 \\
\hline ligp1 & Interferon inducible gtpase 1 & 2.7 & 0.0025 & 0.059 (NS) \\
\hline $\mathrm{Ccl} 8$ & Chemokine (C-C motif) ligand 8 & 2.6 & 0.00037 & 0.019 \\
\hline lsg20 & Interferon-stimulated protein & 2.4 & 0.0048 & 0.086 (NS) \\
\hline $\mathrm{CCl} 4$ & Chemokine (C-C motif) ligand 4 & 2.4 & 0.0012 & 0.039 \\
\hline Cxcl13 & Chemokine (C-X-C motif) ligand 13 & 2.2 & 0.0069 & 0.106 (NS) \\
\hline Cxcl16 & Chemokine (C-X-C motif) ligand 16 & 2.1 & 0.0012 & 0.039 \\
\hline $\mathrm{Ccrl} 2$ & Chemokine (C-C motif) receptor-like 2 & 2.0 & 0.0024 & 0.057 (NS) \\
\hline
\end{tabular}

Shown is the list of ISGs significantly $(p<0.05)$ upregulated $>2$-fold in ex vivo-sorted microglia from the ipsilateral cortex of WT mice $72 \mathrm{~h}$ after tMCA0/R or sham surgery. tMCA0/R and ex vivo flow cytometry sorting of isolated microglia was performed as described in the Materials and Methods. RNA from isolated microglia was processed and analyzed as described in the Materials and Methods. Expression data are normalized to RNA obtained from sorted cortical microglia from cortex of sham-operated mice. Both raw and adjusted $p$-values are shown. NS, Not significant.

tion and if this was dependent on TLR4 and/or IFNAR1. We stimulated WT, IFNAR $1^{-1-}$, and TLR $4^{-1-}$ microglia with HSP70 or LPS, both potent activators of TLR4 (Marsh and Stenzel-Poore, 2008; Weinstein et al., 2010). We found that stimulation with either TLR4 agonist induced robust secretion of CXCL10 and CCL5 in WT microglia (Fig. 6E,F). As expected, stimulation of TLR4 ${ }^{-1-}$ microglia with either HSP70 or LPS elicited little or no secretion of CXCL10 or CCL5. Interestingly, IFNAR $1^{-1-}$ microglia showed markedly reduced CXCL10 release (91\% reduction for HSP70, 94\% reduction for LPS) and smaller but still significant decreases for CCL5 (40\% and 34\% for HSP70 and LPS, respectively). These data demonstrate that TLR4-agonist-induced secretion of ISG chemokines is dependent on TLR4 and at least partially dependent on IFNAR1.

Transcriptome analysis of ex vivo sorted cortical microglia reveals an in vivo ischemia/reperfusion-induced ISG response Our in vitro $\mathrm{H} / \mathrm{H}-\mathrm{N} / \mathrm{N}$ model has some limitations, including cellular energy depletion and absence of communication with (nonmicroglial) CNS cells. Furthermore, previous studies have demonstrated significant differences in the transcriptome of cultured primary microglia from neonatal pups compared with microglia acutely isolated via ex vivo flow cytometry from adult mice (Beutner et al., 2013; Butovsky et al., 2014). We set out to determine whether the ISG response that we saw in primary microglia exposed to $\mathrm{H} / \mathrm{H}-\mathrm{N} / \mathrm{N}$ could also be seen in acutely isolated ex vivo sorted microglia from adult mice after ischemia/reperfusion. To do this, we performed tMCAO/R on adult WT mice, as described in the Materials and Methods. We then used ex vivo flow cytometry to acutely isolate cortical microglia, extracted RNA from these cells, and processed RNA for microarray analysis, as described in the Materials and Methods. We found that in vivo ischemia/reperfusion did in fact induce an ISG response in sorted cortical microglia from the ischemia/reperfusion (tMCAO/R)exposed, but not naive (sham), cortex (Table 3). Overall, the ISG response to in vivo ischemia/reperfusion in sorted microglia was similar to the in vitro microglial response to $\mathrm{H} / \mathrm{H}-\mathrm{N} / \mathrm{N}$, but was broader and more robust. We identified 32 ISG transcripts that were significantly upregulated $>2$-fold, with 12 of these genes upregulated $\geq 4$-fold (Table 3 ). As with the in vitro transcriptome data, a number of upregulated transcripts in vivo were prototypical ISGs, including irf7, oas 1, $m \times 1$, usp 18, and the ISG chemokines cxcl10, cxcl13, and cxcl16 as well as ccl5/rantes.

\section{Ischemia/reperfusion-induced ISG response in vivo is dependent on intact IFNAR1, but not TLR4}

To confirm the in vivo ischemia/reperfusion-induced ISG response in acutely isolated cortical microglia, we performed qRTPCR analyses on ex vivo sorted cortical microglia isolated from the ipsilateral or contralateral cortex from separate cohorts of WT, IFNAR $1^{-1-}$, or TLR $4^{-1-}$ mice that had been exposed to the tMCAO/R paradigm using our panel of primer/probe sets corresponding to six ISGs identified in our microarray. We found that exposure to ischemia/reperfusion significantly increased ex- 


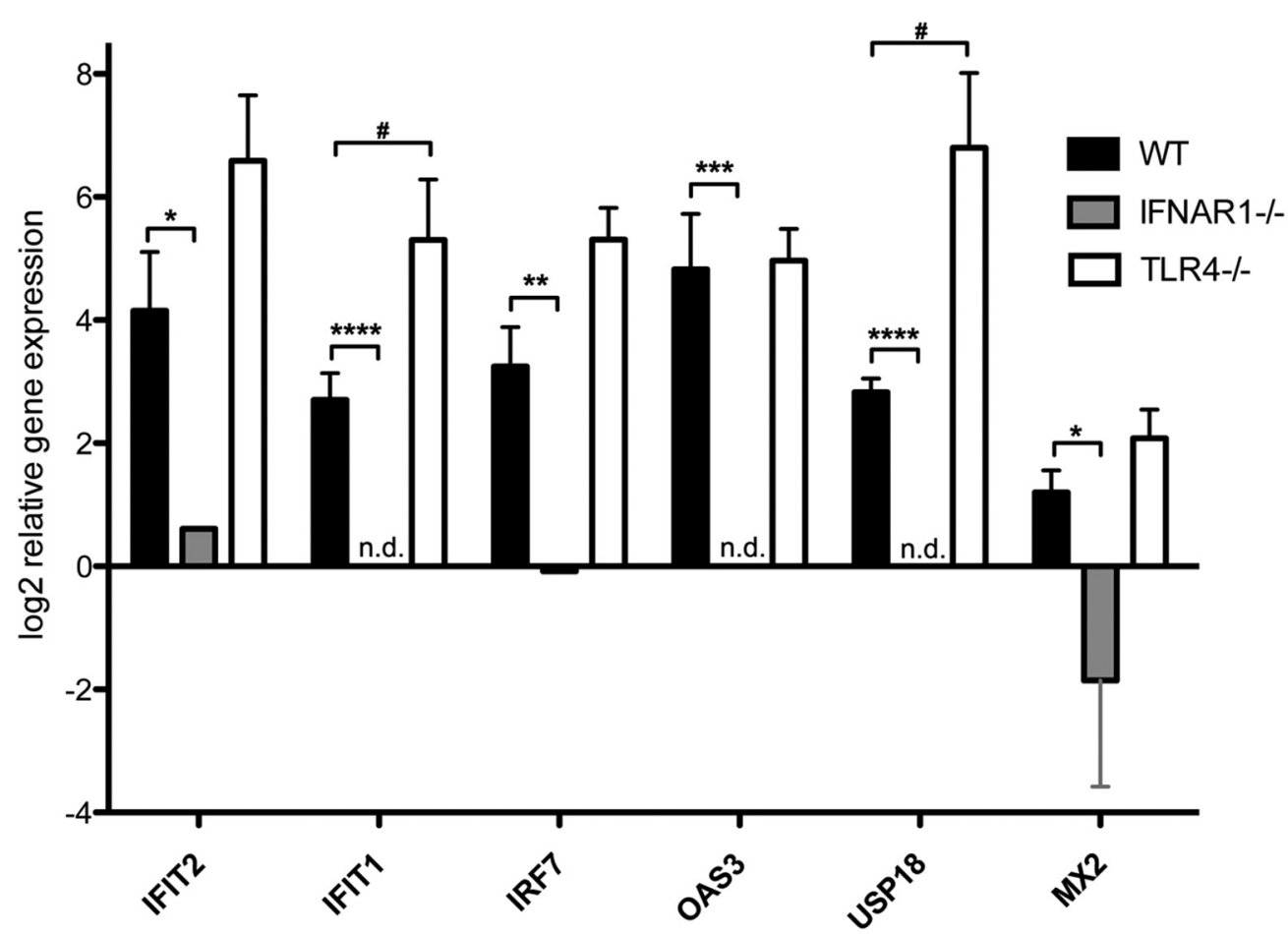

Figure 7. Microglia upregulate ISGs in response to ischemia/reperfusion in vivo and this response is dependent on IFNAR1, but not TLR4. WT, TLR4 ${ }^{-1-}$, and IFNAR1 ${ }^{-1-}$ mice aged $12-14$ weeks were subjected to tMCAO/R before brains were collected and processed as described in the Materials and Methods. Microglia were ex vivo sorted by flow cytometry, microglial RNA was isolated, and qRT-PCR was performed with a selected panel of ISG primer/probe sets as described in the Materials and Methods. Expression data were normalized to a panel of housekeeping genes and are presented relative to expression in microglia isolated from contralateral cortex. $N=12-16$ mice from four separate ex vivo flow cytometry preparations $/$ sorts for each genotype. \#p $<0.05$ between WT and TLR4 ${ }^{-1-} ;{ }^{* *} p<0.01,{ }^{* * *} p<0.001,{ }^{* * * *} p<0.0001$ between WT and IFNAR1 ${ }^{-1-}$. n.d., Not detected. Individual $p$-values for listed genes in a comparison of WT and IFNAR1 ${ }^{-1-}$ animals: ifit2, $p=0.0181 ;$ ifit1, $p<0.0001 ;$ irf7, $p=0.0077 ;$ aas $3, p<0.001 ;$ usp $18, p<0.0001$; and $m \times 2, p=0.0358$. Individual $p$-values for genes significantly different between WT and TLR4 ${ }^{-1-}$ animals: ifit1, $p=0.0442 ;$ usp $18, p=0.0130$.

pression of all six of these ISGs in the WT and TLR $4^{-1-}$, but not the IFNAR $1^{-1-}$, mice (Fig. $7 ; F$ value $=14.89, p=0.0006$, oneway ANOVA). The magnitude of the ISG upregulation in the WT mice varied from $\sim 2$-fold $(m \times 2)$ to $>16$-fold (ifit2 and oas3), which is significantly more robust than the fold changes observed in cultured primary microglia (Fig. 2). These changes were also consistent with those seen in our in vivo microarray data (Table $3)$. As expected, none of the six genes was upregulated in microglia from the IFNAR1 ${ }^{-/-}$mice; however, somewhat unexpectedly, several of the genes (ifit1, $t=2.673, p=0.0442$, unpaired $t$ test; and $u s p 18, t=3.771, p=0.0130$, unpaired $t$ test) showed significantly greater expression in the TLR $4^{-1-}$ microglia compared with the WT microglia (Fig. 7).

\section{Discussion}

This study demonstrates that in response to either $\mathrm{H} / \mathrm{H}-\mathrm{N} / \mathrm{N}$ in vitro or ischemia/reperfusion in vivo, microglia upregulate the expression of ISGs significantly in a process that is dependent on IFNAR1 both in vitro and in vivo and also dependent on TLR4 in vitro, but not in vivo. We also show that $\mathrm{H} / \mathrm{H}-\mathrm{N} / \mathrm{N}$ in vitro induces time dependent changes in the levels of pSTAT1 and hypoxia/hypoglycemia induces marked downregulation of surface expression of IFNAR1, but does not induce release of detectable levels of type 1 IFNs. Furthermore, microglia respond broadly and robustly to stimulation with IFN- $\beta$ both in vitro and in vivo at the level of mRNA transcription and in vitro at the level of protein translation and ISG chemokine secretion. Finally, stimulation with TLR4 agonists induces the release of ISG chemokines in a manner that is partially dependent on IFNAR1.

\section{Convergent ISG response of microglia to} ischemia/reperfusion in vivo bolsters in vitro findings

Several recent studies have described the transcriptional profile of acutely isolated (ex vivo sorted) microglia from naive mice (Hickman et al., 2013; Butovsky et al., 2014) and a few studies have begun to examine the changes in the transcriptome that occur in microglia in neurological disease states (Holtman et al., 2015; Grabert et al., 2016). Interestingly, these studies have identified upregulation of ISGs as an important signature in aging mice (Holtman et al., 2015; Grabert et al., 2016) and in mouse models of Alzheimer's disease (Holtman et al., 2015). Therefore, induction of ISGs may be the consequence of activation of an important and widespread cell signaling pathway in numerous neuropathological conditions (Holtman et al., 2015). However, disease-specific transcriptome changes in acutely isolated, ex vivo sorted microglia are still largely unexplored and present an area of research that has recently been identified as an important topic for further investigation (Crotti and Ransohoff, 2016). In particular, little data are currently available describing changes in the microglial transcriptome in the context of in vivo ischemia/reperfusion (stroke). Therefore, our data here identifying a robust ISG response in microglia acutely isolated from ipsilateral, but not contralateral, cortex $72 \mathrm{~h}$ after transient ischemia/reperfusion is noteworthy.

Possible mechanisms of ischemia/reperfusion and agonist-induced ISG responses in microglia

Our studies examining the effects of $\mathrm{H} / \mathrm{H}-\mathrm{N} / \mathrm{N}$ in vitro and ischemia/reperfusion in vivo on microglia gene expression identified 


\section{A Hypoxia/hypoglycemia} Normoxia/normoglycemia (in vitro)

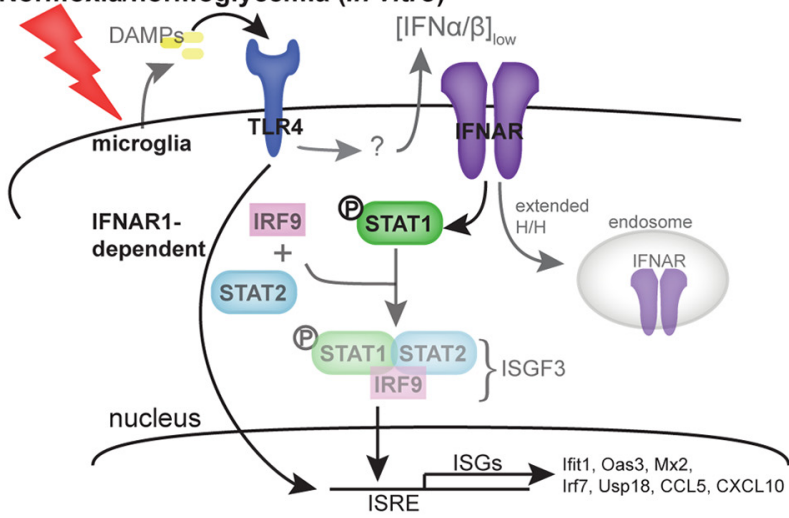

\section{IFN $\beta$ stimulation}

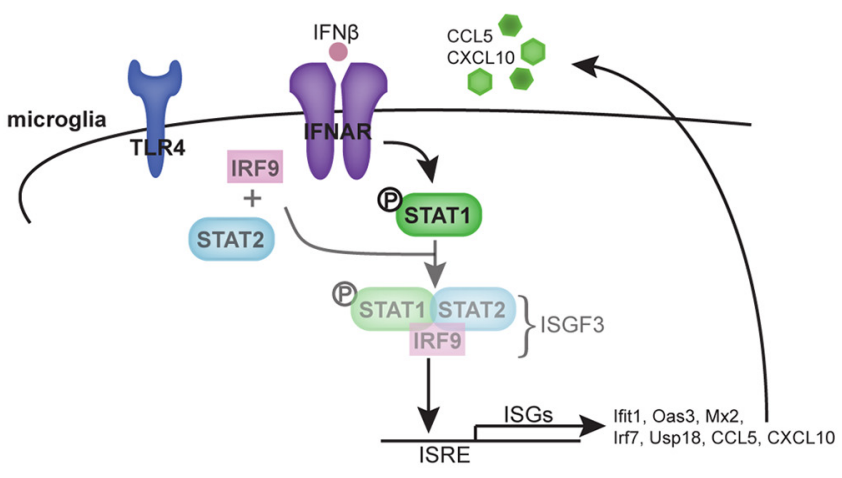

\section{B TLR4 agonist experiments}

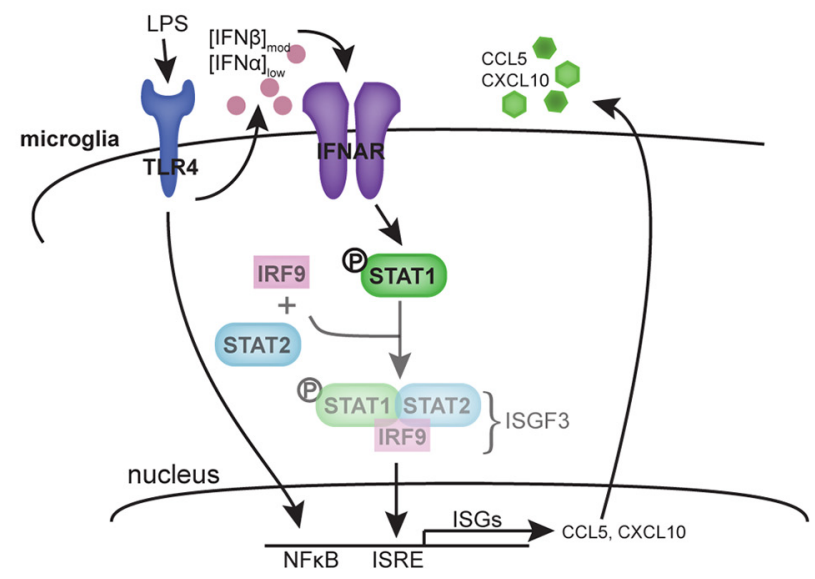

D Ischemia-reperfusion (in vivo)

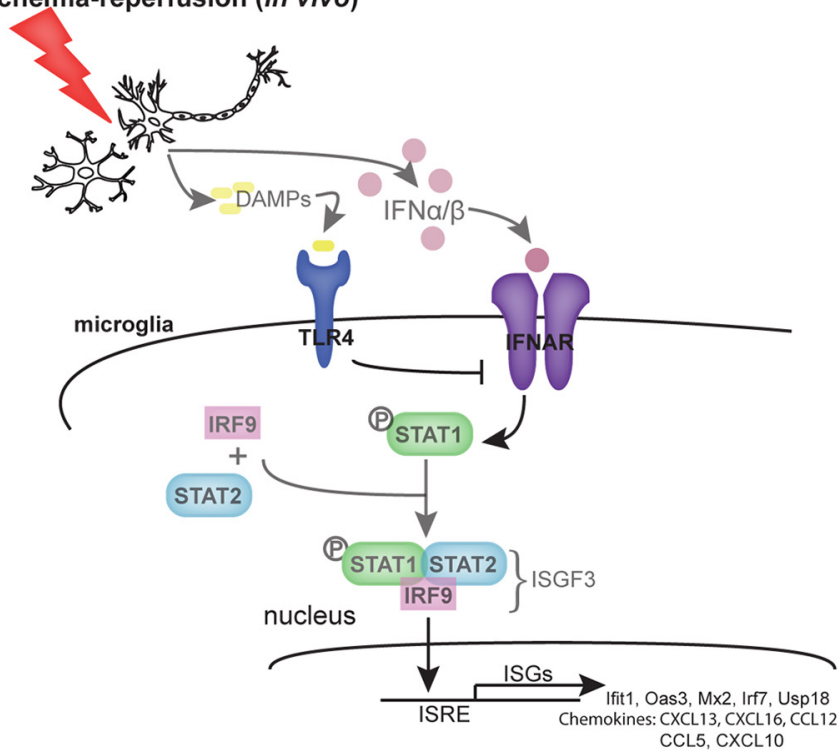

Figure 8. Schematic diagram of microglial responses to ischemia/reperfusion based on our in vitro and in vivo datasets. $A$, When primary microglia in culture are exposed to $\mathrm{H} / \mathrm{H}-\mathrm{N} / \mathrm{N}$, $\mathrm{TLR} 4$ is activated, presumably by DAMPs that are released from the $\mathrm{H} / \mathrm{H}-\mathrm{N} / \mathrm{N}$-exposed microglia. This leads to TLR4- and IFNAR1-dependent ISG expression. Our pSTAT1 assay data in microglia indicates that H/H-N/N exposure alters the phosphorylation state of STAT1, a key mediator in the canonical type I IFN signaling pathway (Stark et al., 1998; Ivashkiv and Donlin, 2014). Following the canonical pathway (Stark et al., 1998; Ivashkiv and Donlin, 2014; McNab et al., 2015), which most likely results in the formation of the ISGF3 TF (shown in gray shaded colors to indicate that this component of the pathway requires further investigation) and transcriptional upregulation of ISGs. Although we did not detect release of type I IFNs (IFN- $\alpha / \beta$ ) by cultured microglia in response to $\mathrm{H} / \mathrm{H}$, it is possible that low concentrations of type I IFNs (and/or type 1 IFN variants not detected by ELISA) are released that signal via IFNAR (Ivashkiv and Donlin, 2014). After extended periods of H/H, we observed a downregulation of IFNAR1 surface expression, which may be due to endosomal sequestration and/or degradation of the surface receptor (shown in gray; Kumar et al., 2003; Kumar et al., 2007; Chmiest et al., 2016). B, In response to stimulation with TLR4 agonists such as LPS or HSP70, cultured microglia release type IIFNs and stimulate the transcription of ISGS, as well as the secretion of ISG chemokines such as CXCL10 and CCL5, into the culture medium. TLR4 is capable of initiating directly TFs that bind to NF $\kappa$ B cis elements in the promoters of CXCL10 and CCL5 (Ohmori and Hamilton, 1993; Lin et al., 1999), whereas TLR4-induced type I IFNs mediate signaling via IFNAR and ISRE cis elements, which are also found in the promoters of CXCL10 and CCL5 (Ohmori and Hamilton, 1993; Lin et al., 1999). The ISG chemokines are then translated and secreted as indicated. C, In response to IFN- $\beta$, microglia also demonstrate robust upregulation of multiple ISGs and dose-dependent secretion of CXCL10 and CCL5. IFN- $\beta$ also induces phosphorylation of STAT1, indicating that signaling proceeds via the canonical type I IFN pathway (shown in gray). $\boldsymbol{D}$, The in vivo response to ischemia/reperfusion is similar to the in vitro response to $\mathrm{H} / \mathrm{H}-\mathrm{N} / \mathrm{N}$ in that both result in a broad and robust IFNAR1-dependent ISG response. However, in contrast to the in vitro response to $\mathrm{H} / \mathrm{H}-\mathrm{N} / \mathrm{N}$, we find that TLR4 is not required for ischemia/reperfusion-induced ISG expression in vivo. Our data suggest instead that TLR4 might have a slight restraining effect on ISG expression or it could be complementary to IFNAR1 in the presence of type IIFNs, which are likely released by other cells of the CNS (Marsh et al., 2009; Gesuete et al., 2012), including astrocytes and neurons (shown in gray). After IFNAR1 is activated by type I IFNs, signaling proceeds, most likely through the canonical pathway involving pSTAT1 and ISGF3 (shown in gray), which induces the transcription of multiple ISGs.

mechanistic commonalities and differences resulting in robust ISG expression in both models. The key similarity between the in vitro and in vivo datasets is that the ISG response was dependent on IFNAR1. In contrast, a key difference is that the in vitro ISG response to $\mathrm{H} / \mathrm{H}-\mathrm{N} / \mathrm{N}$ was dependent on TLR4, whereas the in vivo ISG response was not. To highlight both the similarities and differences, we have generated schematics detailing two related but distinct mechanistic pathways that are consistent with either our in vitro (Fig. $8 A$ ) or in vivo (Fig. $8 D$ ) findings.
For the in vitro model (Fig. 8A), we hypothesize that the TLR4 dependence of the ISG response is the result of microglial release of DAMPs that activate TLR4 on the microglial cell surface (Lehnardt et al., 2008; Qiu et al., 2008; Shichita et al., 2012b). After TLR4 activation, signaling may proceed in an autocrine/paracrine manner through the release of low (undetectable) concentrations of type 1 IFNs or via an alternative ligand-independent pathway leading to direct activation of IFNAR. The former (classical pathway) hypothesis is supported by our data showing that 
the in vitro ISG response is dependent on IFNAR1 and the existence of this pathway is supported indirectly by data demonstrating TLR4 agonist-induced release of IFN- $\beta$ in WT microglia, as well as the finding that TLR4 agonist-induced release of ISG chemokines in microglia was partially dependent on IFNAR1. The non-IFNAR1-dependent component of the chemokine release responses can be explained by binding sites for TLR4responsive TFs $(\mathrm{NF} \kappa \mathrm{B}$ and $\mathrm{AP}-1)$ in the promoter regions of cxcl10 and ccl5 in addition to ISREs (Ohmori and Hamilton, 1993; Lin et al., 1999; Fig. 8B). The classical signaling pathway is also consistent with studies in macrophages demonstrating that LPS induced expression of ISGs in WT, but not If $n b 1^{-1-}$ or Ifnar $^{-1-}$, macrophages (Sheikh et al., 2014). However, the latter possibility (ligand-independent IFNAR activation) is supported by the existence of an "inside-out" signaling pathway that accelerates IFNAR1 turnover in cells undergoing endoplasmic reticulum stress (Liu et al., 2008). This pathway does not require extracellular ligands (i.e., IFN- $\alpha / \beta$ ), but instead relies on activation of intracellular kinases (Liu et al., 2008; Bhattacharya et al., 2011). That we observed rapid phosphorylation of STAT1 as early as 5 min after stimulation at the canonical Tyr-701 location in response to hypoxia/hypoglycemia also argues for the existence of an intracellular pathway that is ligand independent. Nevertheless, our data on this point are limited and not definitive. It is possible that both extracellular and intracellular pathways may be active in this context and other intracellular pathways, such as phosphorylation of a noncanonical STAT1 site (Luu et al., 2014), could play a role, although we have not been able to demonstrate this to date. Further characterization of both ligand-dependent and ligand-independent IFNAR1 activation pathways in $\mathrm{H} / \mathrm{H}-\mathrm{N} / \mathrm{N}-$ exposed microglia is an important direction for future experiments.

For our in vivo model (Fig. 8D), we demonstrate that the ISG response is dependent on IFNAR1, but independent of, and perhaps inhibited by, TLR4. A number of endogenous TLR ligands (DAMPs) are released in response to ischemia/reperfusion (for review, see Gesuete et al., 2014). It is possible that the primary source for type 1 IFNs, as well as other ISGs, in the context of ischemia/reperfusion is as follows: (1) not microglia (Gesuete et al., 2012), (2) microglia that are activated by DAMPs targeting TLRs other than TLR4 (Gesuete et al., 2014), or (3) microglia responding to other non-TLR-based cytosolic pattern recognition receptor systems such as the RIG-I-RNA complexes associated with mitochondrial antiviral signaling protein (Buskiewicz et al., 2016) and nucleotide-binding oligomerization domainlike receptors (Kawai and Akira, 2009). Regardless of the exact cellular source and proximal stimulus for type 1 IFN production in ischemia/reperfusion, it is apparent from their robust in vivo responses to both IFN- $\beta$ and ischemia/reperfusion that microglia represent an important cellular target for type 1 IFNs. It is likely that the IFNAR1-dependent ISG response in vivo proceeds via the canonical STAT1 phosphorylation pathway (Goldmann et al., 2015; Fig. 8D); however, our attempts to confirm this have been limited by available tools and/or rapid temporal dynamics of this response.

\section{Robust microglial response to IFN- $\beta$ identifies potential downstream effectors}

Our data demonstrating robust effects of IFN- $\beta$ on microglial expression of ISGs both in vitro and in vivo provides a striking example of the extent to which type 1 IFNs can alter the microglial transcriptome. In general, chemokines, cytokines, costimulatory, and antigen presentation genes were all strongly upregulated, suggesting a primary innate immune response. The observation that the ISG response to IFN- $\beta$ in vitro was similarly robust in WT and TLR4 ${ }^{-/-}$microglia is consistent with our hypothesis that IFN signaling is either downstream or independent of DAMPinduced TLR4 signaling in ischemia/reperfusion (Fig. 8) and thus TLR 4 can be bypassed by IFN- $\beta$. The IFN- $\beta$-induced increases in ISG chemokine protein release add support to the idea that activation of type 1 IFN signaling in microglia leads to measurable changes in key signaling proteins that can orchestrate leukocyte recruitment (Charo and Ransohoff, 2006; Ransohoff, 2009) and affect neuronal viability directly (Chou et al., 2008). This may be particularly relevant in the context of ischemia/reperfusion, in which genetic deletion of IFN- $\beta$ resulted in marked increases in the poststroke infiltration of inflammatory cells into the brain (Inácio et al., 2015) and administration of IFN- $\beta$ significantly reduced post-MCAO microglial activation, reduced infarct volume, and improved neurobehavioral outcomes (Kuo et al., 2016).

\section{Microglial ISG response may contribute to preconditioning mediated neuroprotection}

Our findings are of interest in light of recent in vivo studies of LPS preconditioning (Marsh et al., 2009; Stevens et al., 2011) and IPC (Stevens et al., 2011) that have demonstrated robust ISG expression in analyses of the transcriptome from whole tissue sections from cortex after an ischemic pulse. However, the cortex is a complex structure containing numerous cell types and a large percentage of cortical RNA is derived from neurons. Robust and functionally important gene expression changes that occur in the smaller and less numerous glial cells, particularly microglia, may be lost in this type of analysis. Our findings that $\mathrm{H} / \mathrm{H}-\mathrm{N} / \mathrm{N}$ in vitro and ischemia/reperfusion in vivo both induce broad ISG expression in microglia provides an important cell-type-specific context for interpreting prior cortical tissue-based findings. From a functional standpoint, type 1 IFN signaling is critical for IPCmediated neuroprotection in both gray-matter-predominant (Stevens et al., 2011) and white-matter-predominant (Hamner et al., 2015) mouse models of ischemic injury and both we (McDonough and Weinstein, 2016) and others (Marsh et al., 2009; Stevens et al., 2011) have proposed that the ISG response in microglia is critical for activating endogenous neuroprotection pathways in ischemia/reperfusion.

\section{References}

Anderson GD, Farin FM, Bammler TK, Beyer RP, Swan AA, Wilkerson HW, Kantor ED, Hoane MR (2011) The effect of progesterone dose on gene expression after traumatic brain injury. J Neurotrauma 28:1827-1843. CrossRef Medline

Benarroch EE (2013) Microglia: Multiple roles in surveillance, circuit shaping, and response to injury. Neurology 81:1079-1088. CrossRef Medline

Beutner C, Linnartz-Gerlach B, Schmidt SV, Beyer M, Mallmann MR, Staratschek-Jox A, Schultze JL, Neumann H (2013) Unique transcriptome signature of mouse microglia. Glia 61:1429-1442. CrossRef Medline

Bhattacharya S, Qian J, Tzimas C, Baker DP, Koumenis C, Diehl JA, Fuchs SY (2011) Role of $\mathrm{p} 38$ protein kinase in the ligand-independent ubiquitination and down-regulation of the IFNAR1 chain of type I interferon receptor. J Biol Chem 286:22069-22076. CrossRef Medline

Brendecke SM, Prinz M (2012) How type I interferons shape myeloid cell function in CNS autoimmunity. J Leukoc Biol 92:479-488. CrossRef Medline

Buskiewicz IA, Montgomery T, Yasewicz EC, Huber SA, Murphy MP, Hartley RC, Kelly R, Crow MK, Perl A, Budd RC, Koenig A (2016) Reactive oxygen species induce virus-independent MAVS oligomerization in systemic lupus erythematosus. Sci Signal 9:ra115. CrossRef Medline

Butovsky O, Jedrychowski MP, Moore CS, Cialic R, Lanser AJ, Gabriely G, Koeglsperger T, Dake B, Wu PM, Doykan CE, Fanek Z, Liu L, Chen Z, 
Rothstein JD, Ransohoff RM, Gygi SP, Antel JP, Weiner HL (2014) Identification of a unique TGF-beta-dependent molecular and functional signature in microglia. Nat Neurosci 17:131-143. CrossRef Medline

Cadena-Herrera D, Esparza-De Lara JE, Ramírez-Ibañez ND, López-Morales CA, Pérez NO, Flores-Ortiz LF, Medina-Rivero E (2015) Validation of three viable-cell counting methods: Manual, semi-automated, and automated. Biotechnol Rep (Amst) 7:9-16. CrossRef Medline

Caso JR, Pradillo JM, Hurtado O, Lorenzo P, Moro MA, Lizasoain I (2007) Toll-like receptor 4 is involved in brain damage and inflammation after experimental stroke. Circulation 115:1599-1608. CrossRef Medline

Charo IF, Ransohoff RM (2006) The many roles of chemokines and chemokine receptors in inflammation. N Engl J Med 354:610-621. CrossRef Medline

Chmiest D, Sharma N, Zanin N, Viaris de Lesegno C, Shafaq-Zadah M, Sibut V, Dingli F, Hupé P, Wilmes S, Piehler J, Loew D, Johannes L, Schreiber G, Lamaze C (2016) Spatiotemporal control of interferon-induced JAK/ STAT signalling and gene transcription by the retromer complex. Nat Commun 7:13476. CrossRef Medline

Chou SY, Weng JY, Lai HL, Liao F, Sun SH, Tu PH, Dickson DW, Chern Y (2008) Expanded-polyglutamine huntingtin protein suppresses the secretion and production of a chemokine (CCL5/RANTES) by astrocytes. J Neurosci 28:3277-3290. CrossRef Medline

Crotti A, Ransohoff RM (2016) Microglial physiology and pathophysiology: insights from genome-wide transcriptional profiling. Immunity 44:505515. CrossRef Medline

Esen N, Kielian T (2007) Effects of low dose GM-CSF on microglial inflammatory profiles to diverse pathogen-associated molecular patterns (PAMPs). J Neuroinflammation 4:10. CrossRef Medline

Fitts DA (2010) Improved stopping rules for the design of efficient smallsample experiments in biomedical and biobehavioral research. Behav Res Methods 42:3-22. CrossRef Medline

Frykholm P, Hillered L, Långström B, Persson L, Valtysson J, Enblad P (2005) Relationship between cerebral blood flow and oxygen metabolism, and extracellular glucose and lactate concentrations during middle cerebral artery occlusion and reperfusion: a microdialysis and positron emission tomography study in nonhuman primates. J Neurosurg 102: 1076-1084. CrossRef Medline

Fuchs SY, Fried VA, Ronai Z (1998) Stress-activated kinases regulate protein stability. Oncogene 17:1483-1490. CrossRef Medline

Gesuete R, Packard AE, Vartanian KB, Conrad VK, Stevens SL, Bahjat FR, Yang T, Stenzel-Poore MP (2012) Poly-ICLC preconditioning protects the blood-brain barrier against ischemic injury in vitro through type I interferon signaling. J Neurochem 123:75-85. CrossRef Medline

Gesuete R, Kohama SG, Stenzel-Poore MP (2014) Toll-like receptors and ischemic brain injury. J Neuropathol Exp Neurol 73:378-386. CrossRef Medline

Giulian D, Baker TJ (1986) Characterization of ameboid microglia isolated from developing mammalian brain. J Neurosci 6:2163-2178. Medline

Goldmann T et al. (2015) USP18 lack in microglia causes destructive interferonopathy of the mouse brain. EMBO J 34:1612-1629. CrossRef Medline

Grabert K, Michoel T, Karavolos MH, Clohisey S, Baillie JK, Stevens MP, Freeman TC, Summers KM, McColl BW (2016) Microglial brain region-dependent diversity and selective regional sensitivities to aging. Nat Neurosci 19:504-516. CrossRef Medline

Hamner MA, Ye Z, Lee RV, Colman JR, Le T, Gong DC, Ransom BR, Weinstein JR (2015) Ischemic preconditioning in white matter: magnitude and mechanism. J Neurosci 35:15599-15611. CrossRef Medline

Hanisch UK, Kettenmann H (2007) Microglia: active sensor and versatile effector cells in the normal and pathologic brain. Nat Neurosci 10:13871394. CrossRef Medline

Hickman SE, Kingery ND, Ohsumi TK, Borowsky ML, Wang LC, Means TK, El Khoury J (2013) The microglial sensome revealed by direct RNA sequencing. Nat Neurosci 16:1896-1905. CrossRef Medline

Holm TH, Draeby D, Owens T (2012) Microglia are required for astroglial Toll-like receptor 4 response and for optimal TLR2 and TLR3 response. Glia 60:630-638. CrossRef Medline

Holtman IR, Raj DD, Miller JA, Schaafsma W, Yin Z, Brouwer N, Wes PD, Möller T, Orre M, Kamphuis W, Hol EM, Boddeke EW, Eggen BJ (2015) Induction of a common microglia gene expression signature by aging and neurodegenerative conditions: a co-expression meta-analysis. Acta Neuropathol Commun 3:31. CrossRef Medline
Hoshino K, Takeuchi O, Kawai T, Sanjo H, Ogawa T, Takeda Y, Takeda K, Akira S (1999) Cutting edge: Toll-like receptor 4 (TLR4)-deficient mice are hyporesponsive to lipopolysaccharide: evidence for TLR4 as the Lps gene product. J Immunol 162:3749-3752. Medline

Hu X, Chen J, Wang L, Ivashkiv LB (2007) Crosstalk among Jak-STAT, Toll-like receptor, and ITAM-dependent pathways in macrophage activation. J Leukoc Biol 82:237-243. CrossRef Medline

Inácio AR, Liu Y, Clausen BH, Svensson M, Kucharz K, Yang Y, Stankovich T, Khorooshi R, Lambertsen KL, Issazadeh-Navikas S, Deierborg T (2015) Endogenous IFN-beta signaling exerts anti-inflammatory actions in experimentally induced focal cerebral ischemia. J Neuroinflammation 12 : 211. CrossRef Medline

Ivashkiv LB, Donlin LT (2014) Regulation of type I interferon responses. Nat Rev Immunol 14:36-49. CrossRef Medline

Janeway CA, Travers P, Walport M, Shlomchik MJ, editors. (2005) Immunobiology: the immune system in health and disease, Ed 6. New York: Garland Science.

Janova $\mathrm{H}$ et al. (2016) CD14 is a key organizer of microglial responses to CNS infection and injury. Glia 64:635-649. CrossRef Medline

Kapil P, Butchi NB, Stohlman SA, Bergmann CC (2012) Oligodendroglia are limited in type I interferon induction and responsiveness in vivo. Glia 60:1555-1566. CrossRef Medline

Karikó K, Weissman D, Welsh FA (2004) Inhibition of toll-like receptor and cytokine signaling-a unifying theme in ischemic tolerance. J Cereb Blood Flow Metab 24:1288-1304. CrossRef Medline

Kawai T, Akira S (2009) The roles of TLRs, RLRs and NLRs in pathogen recognition. Int Immunol 21:317-337. CrossRef Medline

Kettenmann H, Hanisch UK, Noda M, Verkhratsky A (2011) Physiology of microglia. Physiol Rev 91:461-553. CrossRef Medline

Khorooshi R, Owens T (2010) Injury-induced type I IFN signaling regulates inflammatory responses in the central nervous system. J Immunol 185: 1258-1264. CrossRef Medline

Koh JY, Choi DW (1987) Quantitative determination of glutamate mediated cortical neuronal injury in cell culture by lactate dehydrogenase efflux assay. J Neurosci Methods 20:83-90. CrossRef Medline

Kumar KG, Barriere H, Carbone CJ, Liu J, Swaminathan G, Xu P, Li Y, Baker DP, Peng J, Lukacs GL, Fuchs SY (2007) Site-specific ubiquitination exposes a linear motif to promote interferon-alpha receptor endocytosis. J Cell Biol 179:935-950. CrossRef Medline

Kumar KG, Tang W, Ravindranath AK, Clark WA, Croze E, Fuchs SY (2003) SCF(HOS) ubiquitin ligase mediates the ligand-induced down-regulation of the interferon-alpha receptor. EMBO J 22:5480-5490. CrossRef Medline

Kuo PC, Scofield BA, Yu IC, Chang FL, Ganea D, Yen JH (2016) Interferonbeta modulates inflammatory response in cerebral ischemia. J Am Heart Assoc 5: pii: e002610. CrossRef Medline

Laird MD, Shields JS, Sukumari-Ramesh S, Kimbler DE, Fessler RD, Shakir B Youssef P, Yanasak N, Vender JR, Dhandapani KM (2014) High mobility group box protein-1 promotes cerebral edema after traumatic brain injury via activation of toll-like receptor 4. Glia 62:26-38. CrossRef Medline

Lehnardt S (2010) Innate immunity and neuroinflammation in the CNS: the role of microglia in Toll-like receptor-mediated neuronal injury. Glia 58:253-263. CrossRef Medline

Lehnardt S, Schott E, Trimbuch T, Laubisch D, Krueger C, Wulczyn G, Nitsch $\mathrm{R}$, Weber JR (2008) A vicious cycle involving release of heat shock protein 60 from injured cells and activation of toll-like receptor 4 mediates neurodegeneration in the CNS. J Neurosci 28:2320-2331. CrossRef Medline

Lin R, Heylbroeck C, Genin P, Pitha PM, Hiscott J (1999) Essential role of interferon regulatory factor 3 in direct activation of RANTES chemokine transcription. Mol Cell Biol 19:959-966. CrossRef Medline

Liu J, Plotnikov A, Banerjee A, Suresh Kumar KG, Ragimbeau J, Marijanovic Z, Baker DP, Pellegrini S, Fuchs SY (2008) Ligand-independent pathway that controls stability of interferon alpha receptor. Biochem Biophys Res Commun 367:388-393. CrossRef Medline

Liu S, Shi H, Liu W, Furuichi T, Timmins GS, Liu KJ (2004) Interstitial pO2 in ischemic penumbra and core are differentially affected following transient focal cerebral ischemia in rats. J Cereb Blood Flow Metab 24:343349. CrossRef Medline

Liu S, Liu W, Ding W, Miyake M, Rosenberg GA, Liu KJ (2006) Electron paramagnetic resonance-guided normobaric hyperoxia treatment protects the brain by maintaining penumbral oxygenation in a rat model of 
transient focal cerebral ischemia. J Cereb Blood Flow Metab 26:12741284. CrossRef Medline

Longa EZ, Weinstein PR, Carlson S, Cummins R (1989) Reversible middle cerebral artery occlusion without craniectomy in rats. Stroke 20:84-91. CrossRef Medline

Luu K, Greenhill CJ, Majoros A, Decker T, Jenkins BJ, Mansell A (2014) STAT1 plays a role in TLR signal transduction and inflammatory responses. Immunol Cell Biol 92:761-769. CrossRef Medline

Marsh BJ, Stenzel-Poore MP (2008) Toll-like receptors: novel pharmacological targets for the treatment of neurological diseases. Curr Opin Pharmacol 8:8-13. CrossRef Medline

Marsh B, Stevens SL, Packard AE, Gopalan B, Hunter B, Leung PY, Harrington CA, Stenzel-Poore MP (2009) Systemic lipopolysaccharide protects the brain from ischemic injury by reprogramming the response of the brain to stroke: a critical role for IRF3. J Neurosci 29:9839-9849. CrossRef Medline

McDonough A, Weinstein JR (2016) Neuroimmune response in ischemic preconditioning. Neurotherapeutics 13:748-761. CrossRef Medline

McNab F, Mayer-Barber K, Sher A, Wack A, O'Garra A (2015) Type I interferons in infectious disease. Nat Rev Immunol 15:87-103. CrossRef Medline

Michell-Robinson MA, Touil H, Healy LM, Owen DR, Durafourt BA, Bar-Or A, Antel JP, Moore CS (2015) Roles of microglia in brain development, tissue maintenance and repair. Brain 138:1138-1159. CrossRef Medline

Mohr JP, Wolf PA, Grotta JC, Moskowitz MA, Mayberg M, von Kummer R, editors. (2010) Stroke: pathophysiology, diagnosis and management, Ed 5. New York: Churchill Livingstone.

Möller T, Hanisch UK, Ransom BR (2000) Thrombin-induced activation of cultured rodent microglia. J Neurochem 75:1539-1547. Medline

Muhammad S, Barakat W, Stoyanov S, Murikinati S, Yang H, Tracey KJ, Bendszus M, Rossetti G, Nawroth PP, Bierhaus A, Schwaninger M (2008) The HMGB1 receptor RAGE mediates ischemic brain damage. J Neurosci 28:12023-12031. CrossRef Medline

Müller U, Steinhoff U, Reis LF, Hemmi S, Pavlovic J, Zinkernagel RM, Aguet M (1994) Functional role of type I and type II interferons in antiviral defense. Science 264:1918-1921. CrossRef Medline

Ohmori Y, Hamilton TA (1993) Cooperative interaction between interferon (IFN) stimulus response element and kappa B sequence motifs controls IFN gamma- and lipopolysaccharide-stimulated transcription from the murine IP-10 promoter. J Biol Chem 268:6677-6688. Medline

Olson JK, Miller SD (2004) Microglia initiate central nervous system innate and adaptive immune responses through multiple TLRs. J Immunol 173: 3916-3924. CrossRef Medline

Owens T, Khorooshi R, Wlodarczyk A, Asgari N (2014) Interferons in the central nervous system: a few instruments play many tunes. Glia 62:339355. CrossRef Medline

Parajuli B, Sonobe Y, Kawanokuchi J, Doi Y, Noda M, Takeuchi H, Mizuno T, Suzumura A (2012) GM-CSF increases LPS-induced production of proinflammatory mediators via upregulation of TLR4 and CD14 in murine microglia. J Neuroinflammation 9:268. CrossRef Medline

Phipson B, Lee S, Majewski IJ, Alexander WS, Smyth GK (2016) Robust hyperparameter estimation protects against hypervariable genes and improves power to detect differential expression. Ann Appl Stat 10:946-963. CrossRef Medline

Pradillo JM, Fernández-López D, García-Yébenes I, Sobrado M, Hurtado O, Moro MA, Lizasoain I (2009) Toll-like receptor 4 is involved in neuroprotection afforded by ischemic preconditioning. J Neurochem 109:287294. CrossRef Medline

Prinz M, Schmidt H, Mildner A, Knobeloch KP, Hanisch UK, Raasch J, Merkler D, Detje C, Gutcher I, Mages J, Lang R, Martin R, Gold R, Becher B, Brück W, Kalinke U (2008) Distinct and nonredundant in vivo functions of IFNAR on myeloid cells limit autoimmunity in the central nervous system. Immunity 28:675-686. CrossRef Medline

Qiu J, Nishimura M, Wang Y, Sims JR, Qiu S, Savitz SI, Salomone S, Moskowitz MA (2008) Early release of HMGB-1 from neurons after the onset of brain ischemia. J Cereb Blood Flow Metab 28:927-938. CrossRef Medline

Quan Y, Möller T, Weinstein JR (2009) Regulation of Fcgamma receptors and immunoglobulin G-mediated phagocytosis in mouse microglia. Neurosci Lett 464:29-33. CrossRef Medline

Ransohoff RM (2009) Chemokines and chemokine receptors: standing at the crossroads of immunobiology and neurobiology. Immunity 31:711721. CrossRef Medline

Ritchie ME, Phipson B, Wu D, Hu Y, Law CW, Shi W, Smyth GK (2015) limma powers differential expression analyses for RNA-sequencing and microarray studies. Nucleic Acids Res 43:e47. CrossRef Medline

Scheffel J, Regen T, Van Rossum D, Seifert S, Ribes S, Nau R, Parsa R, Harris RA, Boddeke HW, Chuang HN, Pukrop T, Wessels JT, Jürgens T, Merkler D, Brück W, Schnaars M, Simons M, Kettenmann H, Hanisch UK (2012) Toll-like receptor activation reveals developmental reorganization and unmasks responder subsets of microglia. Glia 60:1930-1943. CrossRef Medline

Sheikh F, Dickensheets H, Gamero AM, Vogel SN, Donnelly RP (2014) An essential role for IFN-beta in the induction of IFN-stimulated gene expression by LPS in macrophages. J Leukoc Biol 96:591-600. CrossRef Medline

Shi, et al. (2006) The MicroArray Quality Control (MAQC) project shows inter- and intraplatform reproducibility of gene expression measurements. Nat Biotechnol 24:1151-1161. CrossRef Medline

Shichita T, Hasegawa E, Kimura A, Morita R, Sakaguchi R, Takada I, Sekiya T, Ooboshi H, Kitazono T, Yanagawa T, Ishii T, Takahashi H, Mori S, Nishibori M, Kuroda K, Akira S, Miyake K, Yoshimura A (2012b) Peroxiredoxin family proteins are key initiators of post-ischemic inflammation in the brain. Nat Med 18:911-917. CrossRef Medline

Shichita T, Ago T, Kamouchi M, Kitazono T, Yoshimura A, Ooboshi H (2012a) Novel therapeutic strategies targeting innate immune responses and early inflammation after stroke. J Neurochem 123:29-38. CrossRef Medline

Smyth GK. (2004) Linear models and empirical bayes methods for assessing differential expression in microarray experiments. Stat Appl Genet Mol Biol 3:Article3. Medline

Stark GR, Kerr IM, Williams BR, Silverman RH, Schreiber RD (1998) How cells respond to interferons. Annu Rev Biochem 67:227-264. CrossRef Medline

Stephanou A, Latchman DS (2005) Opposing actions of STAT-1 and STAT-3. Growth Factors 23:177-182. CrossRef Medline

Stevens SL, Leung PY, Vartanian KB, Gopalan B, Yang T, Simon RP, StenzelPoore MP (2011) Multiple preconditioning paradigms converge on interferon regulatory factor-dependent signaling to promote tolerance to ischemic brain injury. J Neurosci 31:8456-8463. CrossRef Medline

Su W, Hopkins S, Nesser NK, Sopher B, Silvestroni A, Ammanuel S, Jayadev S, Möller T, Weinstein J, Garden GA (2014) The p53 transcription factor modulates microglia behavior through microRNA-dependent regulation of c-Maf. J Immunol 192:358-366. CrossRef Medline

Swiatek-Machado K, Kaminska B (2013) STAT signaling in glioma cells. Adv Exp Med Biol 986:189-208. CrossRef Medline

Town T, Jeng D, Alexopoulou L, Tan J, Flavell RA (2006) Microglia recognize double-stranded RNA via TLR3. J Immunol 176:3804-3812. CrossRef Medline

Weinstein JR, Hong S, Kulman JD, Bishop C, Kuniyoshi J, Andersen H, Ransom BR, Hanisch UK, Möller T (2005) Unraveling thrombin's true microglia-activating potential: markedly disparate profiles of pharmaceuticalgrade and commercial-grade thrombin preparations. J Neurochem 95:11771187. CrossRef Medline

Weinstein JR, Koerner IP, Möller T (2010) Microglia in ischemic brain injury. Future Neurol 5:227-246. CrossRef Medline

Witting A, Möller T (2011) Microglia cell culture: a primer for the novice. Methods Mol Biol 758:49-66. CrossRef Medline

Wu Z, Irizarry R, Gentleman RC, Murillo FM, Spencer F (2004) A model based background adjustment for oligonucleotide expression arrays. Journal of the American Statistical Association 99:909-917. CrossRef

Zambelli F, Pesole G, Pavesi G (2009) Pscan: finding overrepresented transcription factor binding site motifs in sequences from co-regulated or coexpressed genes. Nucleic Acids Res 37:W247-W252. CrossRef Medline

Zanoni I, Ostuni R, Marek LR, Barresi S, Barbalat R, Barton GM, Granucci F, Kagan JC (2011) CD14 controls the LPS-induced endocytosis of Tolllike receptor 4. Cell 147:868-880. CrossRef Medline 